\title{
Biologie larvaire et mécanisme de transmission de la Filaire Dipetalonema viteae.
}

\author{
par Odile BAIN (1)
}

\section{SOMMAIRE}

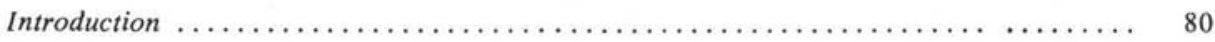

Chapitre $1 .-$ La traversée de la paroi digestive $\ldots \ldots \ldots \ldots \ldots \ldots \ldots \ldots \ldots \ldots \ldots \ldots \ldots$

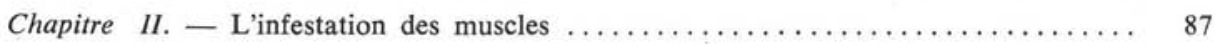

Pénétration des microfilaires dans les fibres musculaires ......... 87

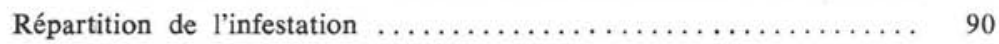

Chapitre 1II. - Le développement des larves; effets sur les organes parasités ..... 92

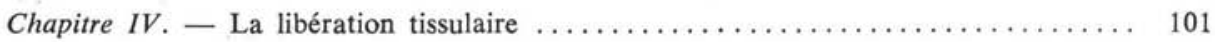

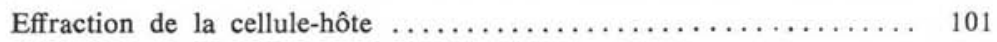

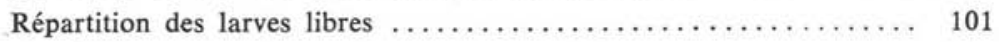

Evolution des muscles anciennement parasités .............. 105

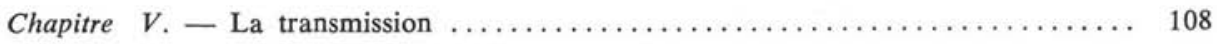

Migration des larves infestantes vers les pièces buccales . . . . . . 108

Sortie des larves infestantes par les pièces buccales ........... 110

Chapitre VI. - L'évolution chez Ornithodoros erraticus ................... 119

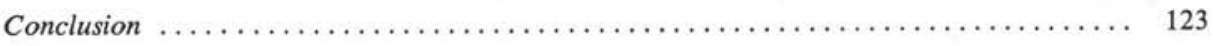

Particularités de la transmission de Dipetalonema viteae ......... 124

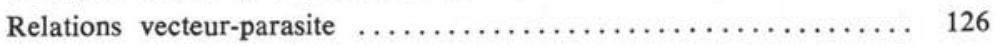

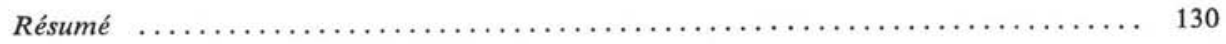

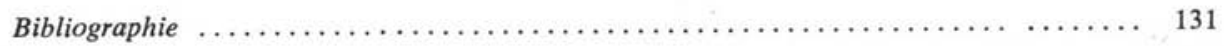

(1) Thèse de Doctorat ès sciences naturelles, $3^{e}$ cycle, Paris, 1966. 


\section{Introduction}

Le Nématode qui fait l'objet de ce travail est une Filaire trouvée en Iran en 1952 par Baltazard, Chabaud et Minou, chez Meriones libycus Licht ; cette souche, adaptée au Hamster, a été entretenue depuis cette époque en laboratoire et nous a été aimablement communiquée par le Professeur J. Biguet.

\section{Discussion taxonomique.}

La désignation de cette filaire donne lieu à quelques discussions taxonomiques : elle fut décrite par Chabaud en 1952 comme espèce nouvelle sous le nom de Dipetalonema blanci; elle fut mise plus tard en synonymie (Chabaud 1957) avec l'espèce Litomosa wite Krepkogorskaya 1933, trouvée au Kazakhstan chez Rhombomys opimus (Lichtenstein). L'espèce fut d'ailleurs retrouvée en Russie et nommée Paracanthocheilonema vite par Buliginskaya, Vladimirov et Markov (1959). L'orthographe originale wite a été modifiée de deux façons différentes: les auteurs russes et Chabaud, à la suite de Skrjabin et Schikhobalova 1948, ont amendé le nom en vite car le B cyrillique se traduit en latin par V et non par W ; ils ne se sont pas préoccupés de la voyelle terminale qu'il y a lieu de mettre à la fin du nom d'auteur auquel l'espèce est dédiée.

D'autres auteurs au contraire, à la suite de Mac Intosh 1935, orthographient witei; c'est là à notre avis une double erreur; le livre de référence américain qui sert de base à toutes ces discussions (Index Catalogue of Medical and Veterinary Zoology, part. 17, 1952) fait figurer l'auteur p. 5336 à Vite et indique P. 5561 «Wite see Vite ». Par ailleurs Lydie Vite est une femme (1). Nous pensons donc que l'orthographe correcte pour désigner la filaire est Dipetalonema viteae (Krepkogorskaya 1933).

\section{Techniques parasitologiques.}

Dipetalonema viteae est maintenue au laboratoire en utilisant comme hôte définitif le Hamster Cricetus auratus, et comme vecteur la Tique Ornithodoros tartakowskyi (Olenev 1931). Les conditions d'élevage et les méthodes d'inoculation sont celles qui ont été décrites par Wattiaux (1964). Nos Tiques, toutefois, sont élevées à $27^{\circ}$ au lieu de $29^{\circ}$.

Pour les besoins de notre travail, nous avons dû aussi infester selon les mêmes techniques Meriones shawi et deux souches d'Ornithodoros erraticus (Lucas 1849), l'une provenant de Vellozo et l'autre de Taghjicht (Maroc) (2).

(1) Nous remercions très vivement notre collègue M. D. Sonin de nous avoir fourni ce renseignement (lettre du 22-11-1965).

(2) La souche *Vellozo * provient de la région de Casablanca ; la souche « Taghjicht » provient du Sud du Maroc; toutes deux nous ont été très aimablement communiquées par M. Baltazard. 


\section{Techniques histologiques.}

Les techniques doivent répondre à deux difficultés inhérentes au matériel d'étude ; l'une concerne la fixation, l'autre l'inclusion.

A) La fixation.

L'Ornithodore se présente comme un sac cuticulaire épais et imperméable. Pour que le fixateur pénètre rapidement, il faut faire des ouvertures artificielles dans la cuticule ; mais, très souvent, les caeca digestifs qui sont moulés sur la face interne de la cuticule sont perforés, entraînant une hémorragie qui gêne les observations histologiques ultérieures.

Finalement nous avons procédé selon deux techniques adaptées au matériel :

1) Fixation des Ornithodores gorgés de sang :

La Tique est plongée dans l'alcool butylique bouillant, afin de coaguler la masse sanguine. Moins d'une minute plus tard, elle est placée dans un fixateur normal après avoir été coupée en deux.

Cette méthode a les inconvénients d'une fixation par la chaleur mais a l'avantage de ne pas modifier l'intégrité des caeca. Le rôle du liquide fixateur est très secondaire; il complète la fixation par la chaleur et rend surtout les tissus plus colorables.

2) Fixation des Ornithodores à jeun :

Dans ce cas, les caeca de la Tique ne sont plus jointifs ; à la loupe binoculaire on peut les observer facilement par transparence ; à l'aide d'une lame de rasoir, on fend le tégument entre les caeca. Puis l'animal est plongé dans le fixateur.

La méthode des incisions a été utilisée parfois pour des Ornithodores gorgés dont les muscles étaient ensuite disséqués et inclus isolément.

Quelles que soient les méthodes utilisées, il faut éliminer l'air contenu dans la Tique dès le début de la fixation; les tubes sont placés dans une cloche à vide et y sont maintenus pendant toute la durée de la fixation.

Les fixateurs utilisés ont été suivant les besoins :

le Bouin aqueux (durée de fixation 3 jours),

le Carnoy ( 2 heures),

le Zenker ( 8 heures),

le Gendre à $0^{\circ}$, et à $-70^{\circ}$ puis $4^{\circ}$ ( 24 heures),

le Rossmann à $0^{\circ}$ (24 heures).

Après la fixation, les pièces sont lavées et mises à ramollir dans l'alcool butylique pendant 5 jours à 1 semaine.

B) L'inclusion.

Les Ornithodores sont inclus dans la paraffine à $56^{\circ}-58^{\circ}$; pour favoriser la pénétration des pièces, ils sont coupés en 2 ou 4 selon leur taille. Un des deux bains de paraffine est fait sous vide. Les blocs ont été coupés à $7,5 \mu$ ou à $5 \mu$. 
C) Les colorations.

Nous n'indiquons que les colorations utilisées pour préciser la nature de certaines structures :

- l'hémalun-picro-indigo-carmin a été très utile pour mettre en évidence les structures chitineuses des pièces buccales ;

- la coloration des nucléoles par la méthode au vert de méthyle-pyronine d’Unna Brachet ;

- la détection du glycogène par le Carmin de Best et le P.A.S. (méthode de Pearse); les résultats sont contrôlés par la digestion salivaire.

\section{Objet du présent travail.}

Le cycle de Dipetalonema viteae a été effectué par Baltazard, Chabaud et Minou (1952) ; l'hôte naturel en Iran est Meriones libycus et le vecteur une Tique présente dans son terrier, Ornithodoros tartakowskyi.

\section{Liste des ABRÉVIATIONS UTILISÉES DANS LES FIGURES ET LES PHOTOS}

\begin{tabular}{|c|c|c|c|}
\hline A. $\mathrm{S}$ & $=$ acinus salivaire. & LE & $=$ leucocyte. \\
\hline A. V & $=$ acinus venimeux. & M & $=$ muscle. \\
\hline C & $=$ cerveau. & M. C & $=$ muscle constricteur du pharynx. \\
\hline $\mathrm{CA}$ & $=$ caecum. & M. D & $=$ muscle dilatateur du pharynx. \\
\hline C. B & $=$ cavité buccale. & M.P & $=$ muscles des pédipalpes. \\
\hline C: DF & $=$ cellule digestive fonctionnelle. & MU & $=$ mue. \\
\hline C. DG & $\begin{array}{l}=\text { cellule digestive avec granula- } \\
\text { tions. }\end{array}$ & $\begin{array}{l}\mathrm{N} \\
\mathrm{O}\end{array}$ & $\begin{array}{l}=\text { noyau. } \\
=\text { ovule. }\end{array}$ \\
\hline $\mathrm{CH}$ & $=$ chélicères. & OE & $=$ œsophage. \\
\hline C. L & $=$ chambre labrale. & O.P & $=$ orifice pharyngien. \\
\hline C. P & $=$ chambre postérieure. & $\mathrm{P}$ & $=$ pédipalpe. \\
\hline C. $\mathrm{S}$ & $=$ canal salivaire. & $\mathrm{P}_{1}$ & $=1^{\mathrm{re}}$ paire de pattes. \\
\hline E & = épistome. & PA & $=$ pharynx. \\
\hline E. D & $=$ épithélium digestif. & P. C & $=$ plaque sous-chélicérienne. \\
\hline $\mathrm{F}$ & $=$ filaire. & $\mathbf{R}$ & $=$ rostre. \\
\hline F. M & $=$ fibre musculaire. & & $=$ salivarium. \\
\hline & $=$ granule. & S. Hy & $=$ sillon hypostomien. \\
\hline GA. M & $=$ gaine de mélanine. & $\mathrm{T}$ & $=$ trachée. \\
\hline G. $\mathrm{H}$ & $=$ gouttière hypostomienne. & TI & $=$ tige. \\
\hline G. $M$ & $=$ grain de mélanine. & T. F & $=$ région céphalique d'une filaire. \\
\hline $\mathrm{H}$ & $=$ hématie. & T. L & $=$ tige labrale. \\
\hline HA & $=$ haemocyte. & V & $=$ vagin. \\
\hline HY & $=$ hypostome & V.E & $=$ vésicule excrétrice. \\
\hline L & $=$ labre. & VU & $=$ vulve. \\
\hline
\end{tabular}

Selon Chabaud (1954) le déroulement de la vie larvaire qui, seule, nous intéresse ici, s'effectue à $28^{\circ}$ de la façon suivante : les microfilaires sanguicoles sont ingérées par 
la Tique au cours d'un repas de sang sur un Mérion infesté ; après avoir traversé la paroi de l'appareil digestif, elles se développent une douzaine de jours dans l'haemocoele, puis parasitent les fibres musculaires; la larve ne présente pas de «stade en saucisse »; la première mue s'effectue vers le $12^{\circ}$ jour, la deuxième vers le $20^{\circ}$ jour ; au $3^{e}$ stade, les larves se libèrent et se répandent dans la cavité générale de l'Ornithodore. L'infestation du Mérion ne peut se faire par voie buccale ; les larves infestantes sont transmises par piqûre lors d'un nouveau repas de sang de la Tique sur le Mérion ; Chabaud observe, sur une Tique qu'il a détachée en cours de repas, six larves qui glissent entre l'hypostome et les chélicères.

Comme il subsistait quelques imprécisions sur la localisation exacte de la larve au début de son développement et sur son mode de transmission, il nous a paru intéressant d'étudier ces questions par les méthodes histologiques.

Nos observations nous ont fait aborder différents problèmes, et particulièrement celui des relations entre la larve-parasite et l'hôte-vecteur; c'est pourquoi nous avons étudié parallèlement le développement larvaire de Dipetalonema viteae chez $O$. erraticus, vecteur reconnu réfractaire ou tout au moins peu réceptif.

\section{CHAPITRE 1}

\section{La traversée de la paroi digestive}

Mis à piquer sur un Hamster infesté, l'Ornithodore pompe le sang plus ou moins riche en microfilaires. Le sang qui afflue emplit d'abord les caeca digestifs les plus proches du débouché de l'œsophage ; mais à la fin du repas, tous les caeca sont régulièrement gonflés de sang.

Sur des coupes provenant d'une Tique fixée une heure après le repas, on retrouve aisément, parmi les hématies, des sections transversales ou obliques de microfilaires. On les rencontre aussi bien dans le caecum sous-œsophagien que dans les caeca latéraux se dirigeant vers les pattes, et dans les caeca dorsaux et postérieurs. Les microfilaires se répandent donc au hasard dans les diverticu'es digestifs, entraînés par l'afflux de sang.

Le passage des microfilaires dans la cavité générale des Tiques soulève des problèmes particuliers car la paroi digestive change totalement d'aspect au cours de la digestion d'un repas.

- Une heure après le repas, elle se présente comme un épithélium simple formé de cellules très plates, dont seuls les noyaux, aplatis eux aussi, sont nettement visibles; ceux-ci sont espacés; les hématies ingérées ne sont séparées de la cavité générale que par les 2 membranes cytoplasmiques des cellules digestives appliquées l'une contre l'autre. Une coloration par le P.A.S. met aussi en évidence une forte basale, mais il n'y a ni doublure musculaire à l'extérieur de la paroi, ni revêtement chitinoïde sur la face 
interne. Cette structure est très constante, quel que soit le caecum étudié. De place en place, sur cet épithélium très mince et fragile, fait saillie le renflement d'une cellule digestive dont le cytoplasme est resté gonflé par 'es produits de digestion du repas précédent (fig. $1 \mathrm{~A}$, photo 1 ).

- Huit heures après le repas, plusieurs cellules digestives apparaissent gonflées, avec un gros noyau central et un nucléole net. Des cellules de ce type deviendront de plus en plus abondantes au fur et à mesure que progresse la digestion, l'épithélium
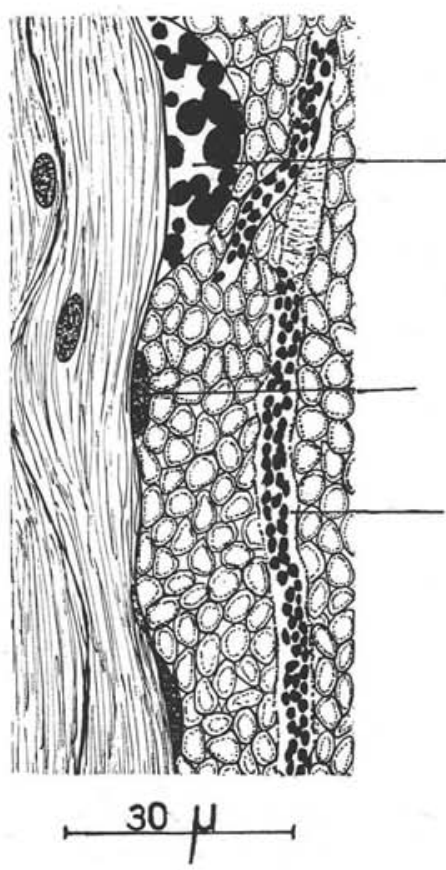

A
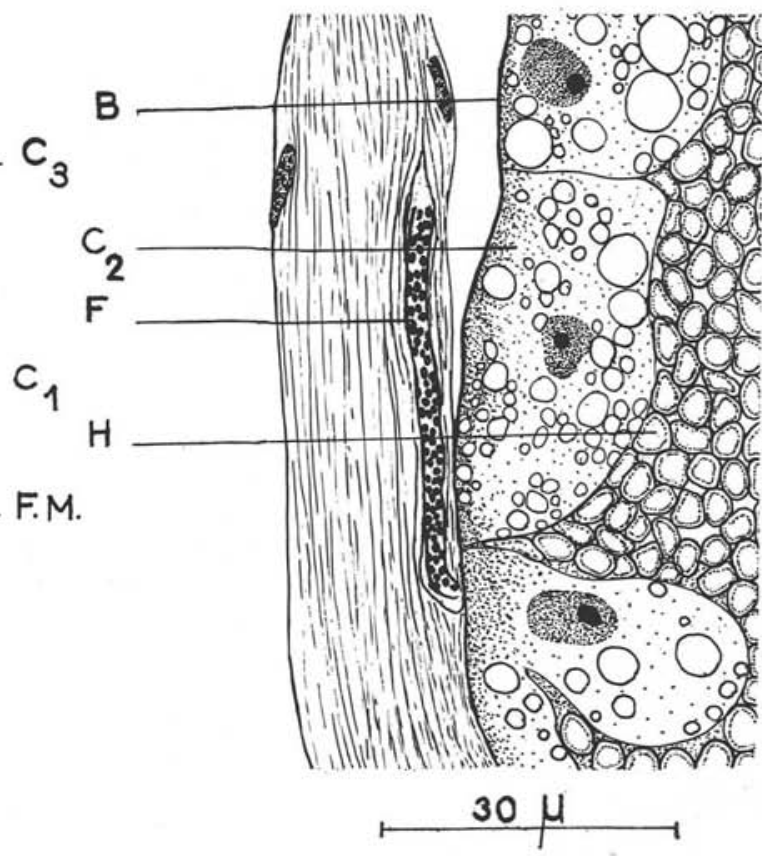

B

FIG. 1. - Deux coupes de l'épithélium digestif d’Ornithodores fixés 24 heures après le repas: A) portion non active avec cellules aplaties; on voit aussi une microfilaire entourée d'une gaine de mélanine ; B) portion active de la paroi digestive

aplati se transformant peu à peu en une épaisse paroi cellulaire (fig. $1 \mathrm{~B}$, photo 2). Mais pendant les premiers jours, d'importantes portions d'épithélium mince persistent entre les cellules digestives en croissance.

Nous avons pu observer sur le vivant le passage des microfilaires à travers cet épithé ium. Des Ornithodores ont été nourris sur un Hamster très infesté (500 microfilaires par goutte de sang), puis disséqués dans l'eau physiologique à $6 \%$; il y a une hémorragie inévitable en ouvrant le tégument de la Tique, mais il est facile de recueillir quelques diverticules digestifs intacts qui sont montés entre lame et lamelle, dans une 
goutte d'eau salée (pour empêcher la dessication de la préparation, on remet une goutte d'eau douce de temps en temps).

1) La première dissection a été faite deux heures après le repas. Les caeca sont alors emplis de microfilaires qui s'agitent frénétiquement et brassent les hématies. Leurs contorsions paraissent aussi désordonnées que lorsqu'elles sont dans le sang du Hamster, mais elles sont plus rapides. Cette augmentation de l'activité des microfilaires chez l'Ornithodore n'est pas immédiate ; en effet, si on compare, sitôt après le repas, une

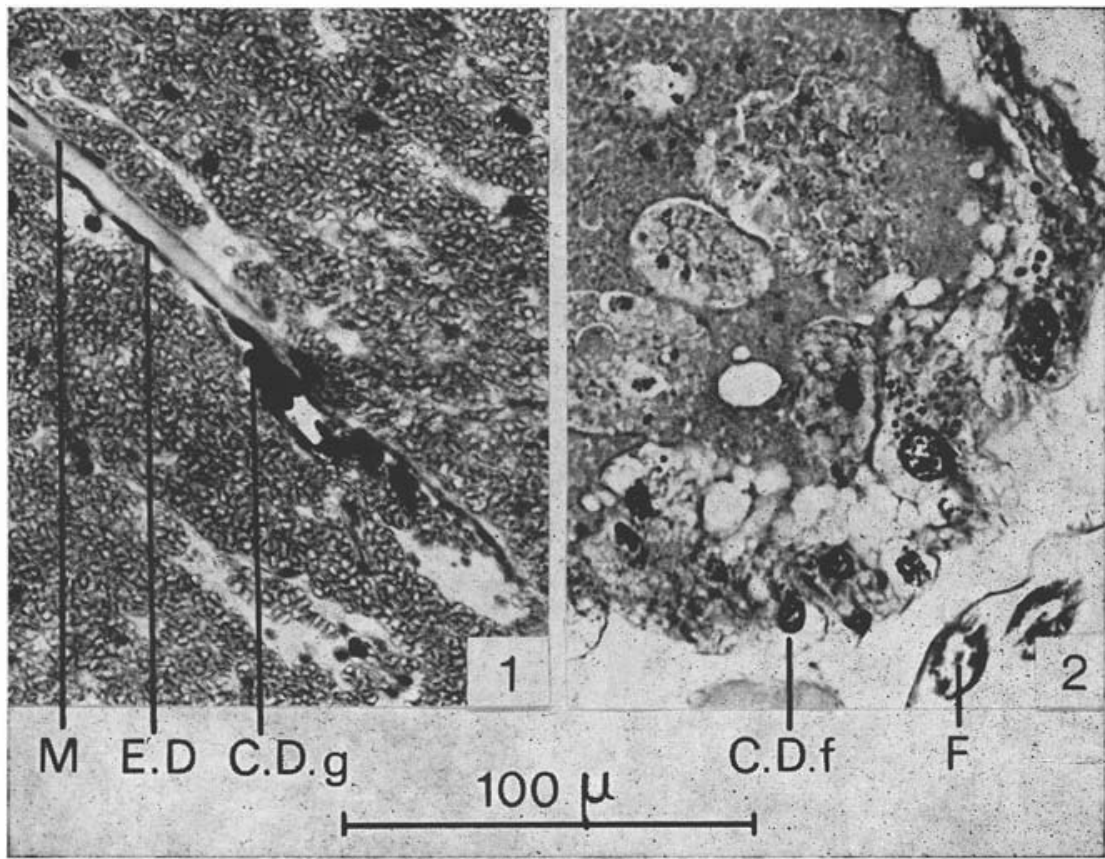

Рното 1. - Epithélium digestif d'Ornithodoros tartakowskyi: une heure après le repas Рното 2. - Idem : 25 jours après le repas

goutte du sang ingéré par l'Ornithodore avec une goutte prélevée chez le Hamster sur lequel il s'est gorgé, on constate que les microfilaires se meuvent avec la même rapidité dans les deux cas.

Dans les caeca observés, toutes les microfilaires ne sont pas dans la masse sanguine centrale. Bon nombre d'entre elles sont contre la paroi épithéliale ou à moitié sorties et encore attachées à la paroi ; celle-ci est bien visible, avec des noyaux distincts. Les microfilaires s'agitent sur place, et frappent la paroi digestive de façon quelconque, la déformant et la distendant ; cependant, lorsque la tête rencontre la paroi, elle s'immobilise un instant et toute la région antérieure paraît effectuer un mouvement coordonné comparable à celui d'une vrille. 
Parmi les très nombreuses microfilaires qui traversent les caeca, c'est parfois l'extrémité postérieure, longue et pointue, qui s'agite à l'extérieur, parfois l'extrémité antérieure, arrondie. La microfilaire finit par se détacher de la paroi caecale mais, dans ces conditions d'observation, la sortie complète de la larve est longue (une heure et plus).

Nous n'avons pu voir sur le vivant de points de rupture dans l'épithélium, ni d'échappées d'hématies après la sortie des microfilaires; pourtant, si l'on suit un lot d'Ornithodores nourris sur un Hamster dont la microfilarémie est supérieure à 50 , on constate que, au bout de 24 heures, la plupart meurent d'hémorragie, les pattes rouges de sang.

2) Les autres dissections effectuées $3 \mathrm{~h}, 5 \mathrm{~h}, 7 \mathrm{~h}$ et $19 \mathrm{~h}$ après le repas, ont montré les mêmes caecà hérissés de-microfilaires à moitié libres et en contenant encore un grand nombre très actives.

Les conclusions que nous pouvons tirer de ces observations sont les suivantes:

1) Les microfilaires qui arrivent dans les caeca deviennent peu à peu plus actives et sortent en provoquant des effractions dans l'épithélium digestif, très mince au moment du repas. Cette traversée nous apparaît essentiellement comme un phénomène mécanique ; mais rien ne s'oppose à imaginer une action enzymatique de la microfilaire sur la paroi digestive, soit par toute sa surface, soit seulement par la région céphalique, comme le laisse supposer la présence de phosphatases acides dans cette région (Petithory, 1965).

2) La pénétration de la paroi se fait tantôt par la région antérieure, tantôt par la région postérieure.

3) Cette traversée se fait en des points quelconques des caeca, ce qui est logique étant donnée la structure uniforme de leurs parois.

4) La sortie des microfilaires hors des caeca débute dès l'ingestion du repas, mais elle est prolongée dans le temps et peut durer 24 à $48 \mathrm{~h}$.

Toutes les microfilaires ingérées ne réussissent pas à passer dans l'haemocoele de l'Ornithodore. A côté des microfilaires saines dont les noyaux sont normalement colorés par l'hémalun, il en existe d'autres dont les noyaux prennent mal le colorant ou sont noirâtres; parfois leur corps est couvert d'un semis de grains de mélanine, ceux-ci s'agglomérant souvent pour former une véritable gaine qui, sur les coupes, peut curieusement paraître détachée de la microfilaire (fig. 1).

La destruction dans les caeca d'un certain pourcentage des microfilaires est un phénomène qui peut être très rapide : certaines microfilaires sont complètement mélanisées au bout d'une heure; dans d'autres cas, cette destruction est plus lente et ne s'accompagne pas de mélanisation ; 3 jours après le repas, quelques filaires persistent, faiblement mobiles, sans structure nucléaire, à aspect vacuolaire, et aux extrémités pas nettes. Il faut noter que la mélanisation se fait aussi bien en plein cœur de la masse sanguine que près des cellules digestives. Les enzymes qui en sont responsables, provenant des cellules digestives, doivent diffuser rapidement. Ces cadavres de filaires doi- 
vent être éliminés ensuite dans la vésicule excrétrice par la même voie que les déchets de la digestion du sang.

Chez un Ornithodore mort d'hémorragie 24 heures après le repas, les microfilaires sont toutes immobiles et mortes; le sang lui-même présente un aspect particulier: toutes les hématies sont éclatées. En goutte épaisse, après coloration au Giemsa, les filaires présentent des noyaux peu colorables.

En résumé, la sortie des microfilaires paraît dépendre du hasard qui leur fait rencontrer la paroi digestive. Plus tôt cette rencontre a lieu, plus elles ont de chances d'échapper à la destruction intracaecale.

Après ce court séjour dans l'appareil digestif, qui constitue un premier mais lâche barrage à l'invasion parasitaire, les microfilaires sont dans l'haemocoele et vont infester les fibres musculaires.

\section{CHAPITRE II}

\section{L'infestation des muscles}

\section{Pénétration des microfilaires dans les fibres musculaires.}

Pendant le passage dans la cavité générale, l'observation de frottis frais et les coupes ont toujours montré que les microfilaires sont libres; les haemocytes sont nombreux dans le sang de l'Ornithodore, mais ils ne s'agglomèrent pas autour des parasites et ne forment jamais de capsule (photo 3 ).

La pénétration proprement dite des microfilaires dans les muscles a été étudiée d'abord par la technique des coupes; mais la dissection d'Ornithodores, suivie d'un examen des fibres musculaires dans l'eau physiologique à $6 \%$ a permis de mieux comprendre le phénomène.

Nous avons pu faire les constatations suivantes:

1. - Les microfilaires, après avoir traversé les caeca digestifs, continuent à être très mobiles; leur rapidité est comparable à celle qu'elles avaient dans les caeca. Mais « in vitro» cette activité est peu efficace: les microfilaires se déplacent peu; celles qui sont assez éloignées des muscles ne semblent pas être attirées par eux. Chez l'Ornithodore, 3 heures après le repas, nous avons trouvé 2 microfilaires dans les chélicères et, 7 heures après le repas, plusieurs autres dans les articles distaux des pattes. Peut-être pour expliquer ces déplacements, faut-il faire intervenir les mouvements propres de l'haemocoele chez l'Ornithodore, les microfilaires étant entraînées passivement vers divers muscles. D'autre part, il est possible que,-dans les préparations, la lamelle freine et perturbe les mouvements naturels des microfilaires.

2. - Bon nombre de microfilaires sont entre les muscles; quelques-unes ont un comportement particulier : nous avons observé ainsi à plusieurs reprises une filaire qui 
enserre une fibre musculaire, perpendiculairement à son grand axe ; elle glisse longuement sur cette fibre ; celle-ci ne présente aucune modification particulière de sa surface. Nous n'avons pu voir le moment de la pénétration d'une microfilaire dans un muscle.
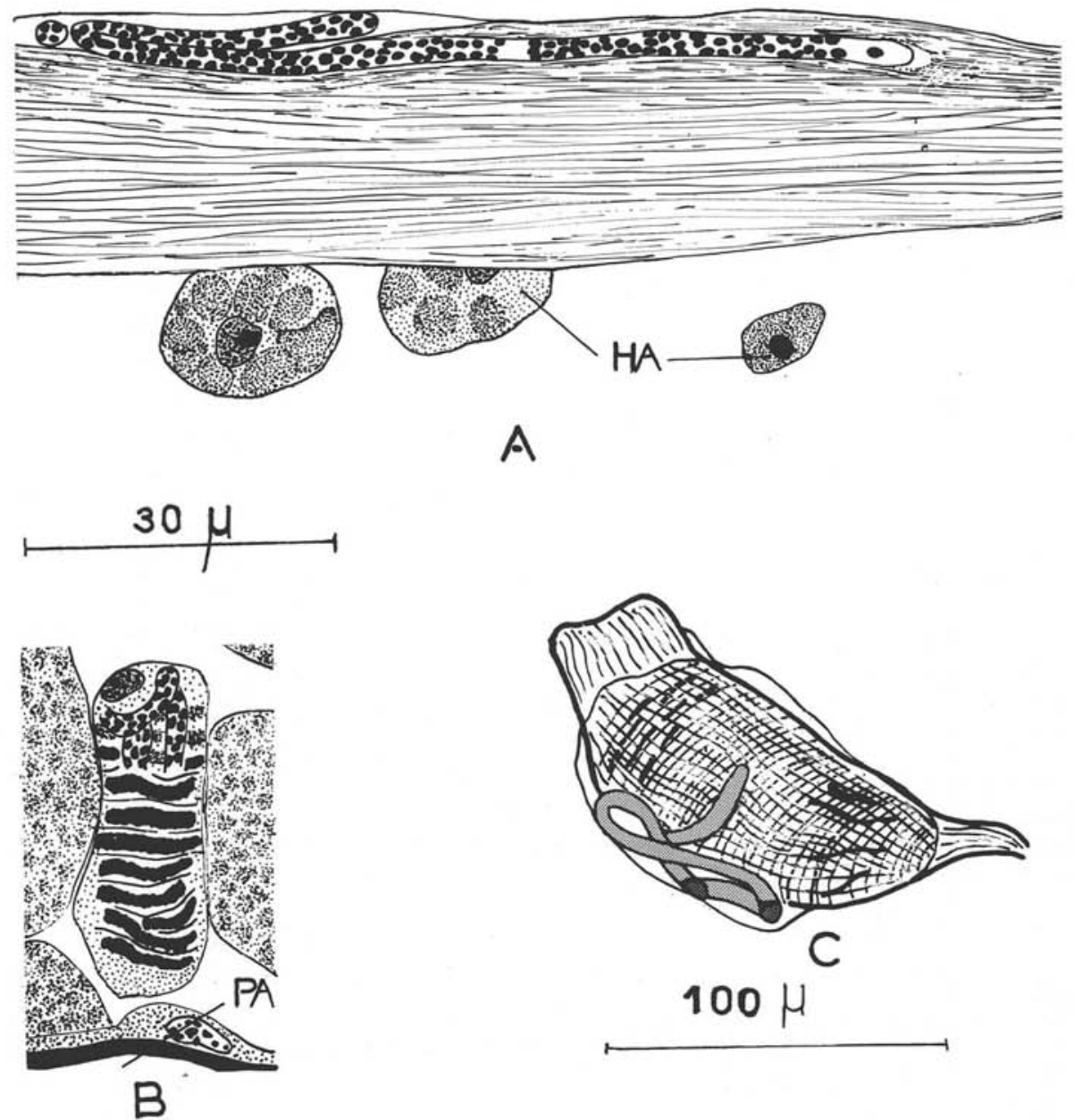

FIG. 2. - A et B) Microfilaires âgées de 24 heures dans une fibre lisse et une fibre striée pharyngienne ; C) microfilaire âgée de 19 heures dans une fibre musculaire striée (dissection sans fixation)

3. - Mais, 19 heures après le repas, nous avons observé une microfilaire dans une fibre musculaire striée. Sur celle-ci, on discerne sans aucune coloration spéciale la mince couche de cytoplasme périphérique contenant les noyaux, et le myoplasme central; la microfilaire occupe la couche cytoplasmique superficielle indifférenciée et laisse intactes les myofibrilles; dans la cellule musculaire, elle est encore mobile : par ses ondulations, elle déforme le sarcolemme (fig. 2 C). 
La rareté des musc'es infestés 19 heures après l'ingestion du sang semble être en contradiction avec les résultats obtenus sur coupe ; en effet, dans ces conditions, dès 8 heures après le repas, de nombreux muscles contiennent des microfilaires.

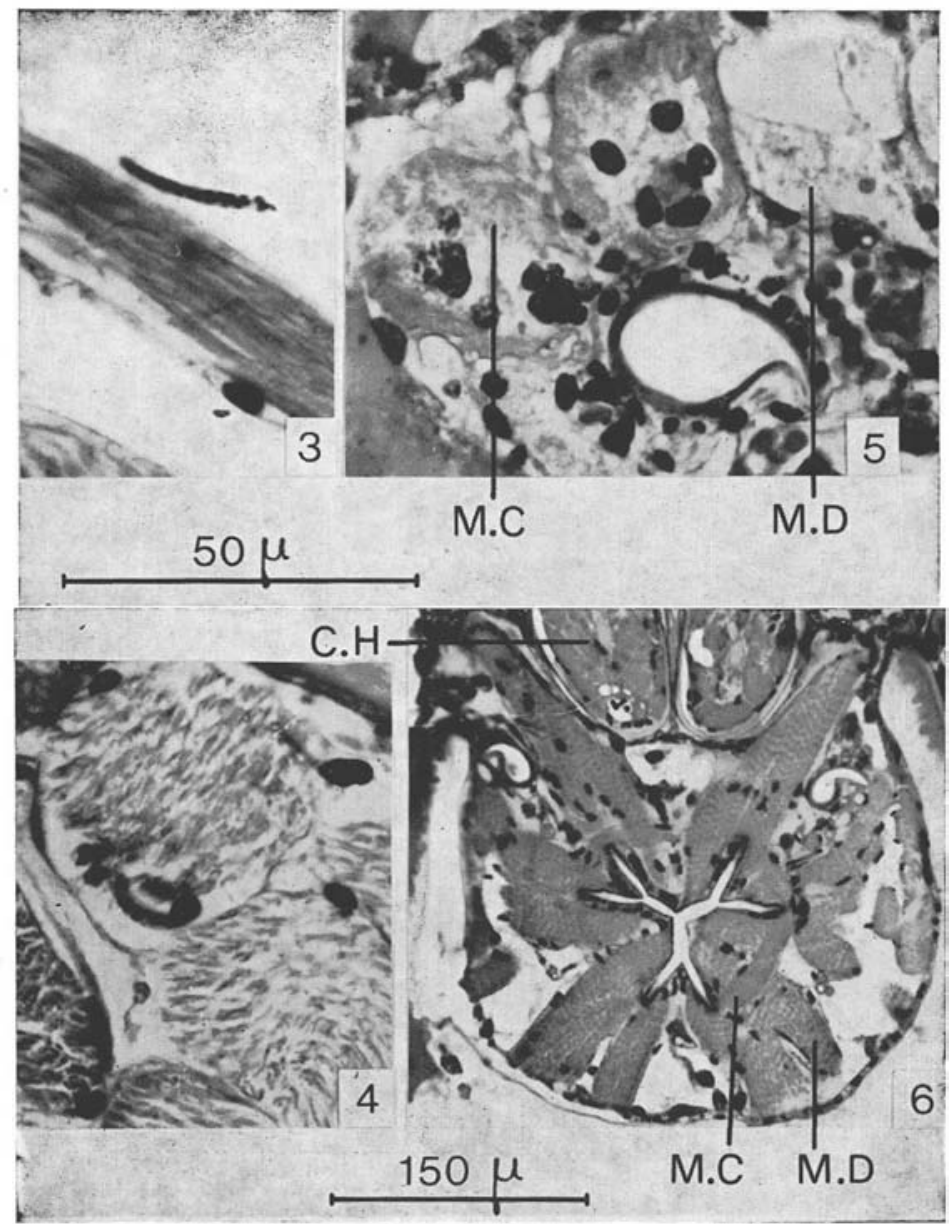

Pното 3. - Microfilaire dans la cavité générale près d'un muscle (24 heures) (échelle : $50 \mathrm{u}$ ) Рното 4. - Microfilaire dans un muscle strié de patte (24 heures) (échelle : $50 \mu$ )

Pното 5. - Détail d'une glande salivaire montrant le canal salivaire et les deux types de cellules sécrétrices (échelle : $50 \mu$ )

Рното 6. - Musculature pharyngienne saine, en coupe transversale (échelle: $150 \mu$ )

Dans les montages frais, certains muscles infestés ont pu échapper à notre observation ; mais il est très probable que les microfilaires peuvent facilement à ce stade se libérer des cellules musculaires, soit naturellement, soit en profitant d'infimes lésions faites sur les muscles pendant la dissection. 
4. - Les fibres musculaires infestées ne présentent aucune modification cytologique permettant de les distinguer des fibres saines, à part une déformation du sarcolemme, déjà signalée. Cette observation est confirmée par les études effectuées sur coupes, 8 heures ou 24 heures après le repas (fig. $2 \mathrm{~A}$, photo 4 ).

En conclusion, la pénétration des fibres musculaires par les microfilaires est un phénomène qui se déroule rapidement et il semble que l'infestation dépende de la rencontre fortuite des parasites avec les muscles.

Les microfilaires ne parasitent d'ailleurs pas exclusivement les fibres musculaires ; les acini venimeux, annexés à l'appareil salivaire (fig. $9 \mathrm{D}$, photo 5), en referment assez souvent, à l'exclusion des cellules salivaires proprement dites, reconnaissables à leurs gros granules de sécrétions. Les raisons de cette variation dans le choix de la cellulehôte nous échappent encore ; mais il faut remarquer que le cytoplasme des cellules venimeuses contient, comme le muscle, un glycogène, facilement coloré par le P.A.S. ou le carmin de Best, qui disparaît après action de la salive. Les cellules salivaires «sensu stricto $»$ n'en renferment pas.

\section{Répartition de l'infestation.}

La musculature d'une Tique n'est pas homogène ; on peut distinguer un système musculaire lisse et un système musculaire strié.

$\mathrm{Au}$ premier appartiennent les muscles des chélicères, les muscles transversaux, et les muscles dorso-ventraux ; ceux-ci sont particulièrement développés. Les fibres dont ils sont formés vont d'un seul tenant du tégument ventral au tégument dorsal, atteignant une longueur de 1 à $1,5 \mathrm{~mm}$; leur diamètre est d'environ 60 à $80 \mu$. Chez les Tiques gorgées, les caeca digestifs sont étroitement accolés à ces muscles.

$\mathrm{Au}$ deuxième système appartiennent les muscles des pattes et ceux du pharynx. La musculature du pharynx est constituée par des plans de 6 fibres musculaires, à disposition rayonnante, qui s'insèrent d'une part sur le pharynx chitineux, d'autre part sur la plaque chitineuse sous-chélicérienne pour les fibres dorsales et sur le tégument du rostre pour les fibres latérales et ventrales (photo 6). Les fibres dorsales les plus développées atteignent $0,20 \mathrm{~mm}$ de long. Chaque plan de 6 fibres est séparé des plans voisins par une fibre musculaire circulaire, qui atteint $450 \mu$ de long et ne dépasse pas $15 \mu$ de large.

A ces deux systèmes, il faut ajouter les fibres lisses très étroites qui supportent la paroi du vagin chez les Tiques femelles.

Chaque fibre musculaire présente un cytoplasme périphérique homogène très mince, surtout chez les fibres lisses, et limité par le sarcolemme ; ce cytoplasme contient des noyaux généralement ovales, mais un peu aplatis. L'essentiel de la fibre est formé par les fibrilles parallèles, lisses ou striées, du myoplasme.

On peut se demander si les microfilaires infestent de façon préférentielle l'un ou l'autre de ces types de muscles. Or, sur toutes les coupes étudiées, nous avons observé des filaires aussi bien dans les muscles striés (fig. 2 B) que dans les muscles lisses, sans constater une plus grande abondance de parasites dans l'un ou l'autre système musculaire. Les muscles du vagin sont eux-mêmes parasités. 
Dans les cas où des larves de filaires se développent dans la musculature des Insectes, en général seuls les muscles thoraciques sont infestés. Il n'en est pas de même chez la Tique que nous étudions. En effectuant des coupes sériées de toute la longueur de la Tique, on retrouve des microfilaires aussi bien dans les muscles postérieurs que dans les muscles antérieurs. Si on effectue un comptage des sections des filaires observées sur des coupes effectuées à différents niveaux du corps, on observe toutefois un chiffre absolu plus élevé pour la zone allant du rostre au pore génital.

Mais ces chiffres n'ont de valeur que si l'on tient compte de la surface de muscle disponible à ces mêmes niveaux du corps. Or, une étude anatomique grossière permet de diviser la Tique en deux parties : une moitié antérieure contenant l'importante musculature pharyngienne et celle des quatre paires d'appendices, à laquelle il faut ajouter les muscles lisses des chélicères et les muscles dorso-ventraux; une moitié postérieure ne contenant que des muscles dorso-ventraux.

Dans un deuxième temps, nous avons donc essayé de rapporter les chiffres précédents à la surface musculaire.

Le comptage des filaires a été fait sur une Tique infestée depuis 24 heures, coupée transversalement. Ont été étudiées: une coupe A passant au milieu du pharynx, une coupe $\mathrm{B}$ passant au niveau de la $2^{\circ}$ paire de pattes et une coupe $\mathrm{C}$ passant en arrière des pattes, mais en avant du pore excréteur. Sur chaque coupe, les muscles sont dessinés à la chambre claire, puis reproduits à l'aide d'un calque sur un carton épais ; celui-ci est découpé et pesé ; son poids est proportionnel à la surface musculaire de chaque coupe.

Les résultats obtenus sont les suivants:

Coupe A : $66 \mathrm{cg}$ et 9 sections de filaires. - Coupe B : $82 \mathrm{cg}$ et 9 sections de filaires. - Coupe C: $14 \mathrm{cg}$ et 2 sections de filaires.

$$
\text { Les rapports } \frac{\text { nombre de filaires }}{\text { poids des cartons }} \text { sont : }
$$

$$
\mathrm{A}=\frac{9}{66}=\frac{2.583}{18.942} \quad \mathrm{~B}=\frac{82}{9}=\frac{2.079}{18.942} \quad \mathrm{C}=\frac{2}{14}=\frac{4.059}{18.942}
$$

En conclusion, il apparaît que les filaires ont une répartition quelconque chez Ornithodoros tartakowskyi. Ceci est en relation avec le fait que les filaires peuvent sortir par toute la surface des caeca. L'infestation apparemment plus forte de la région antérieure de la Tique est due essentiellement à une plus grande richesse en muscles de cette région. 


\section{CHAPITRE III}

\section{Le développement des larves. Effets sur les organes parasités}

Nous avons vu dans un précédent chapitre que les microfilaires ne restaient pas longtemps dans la cavité généra!e de l'Ornithodore, mais se logeaient rapidement dans les fibres musculaires; la même fibre peut recevoir jusqu'à 3 ou 4 filaires.

Cette période de vie intracellulaire a été suivie en utilisant trois techniques d'étude qui se sont avérées chacune indispensable et qui se complètent mutuellement.

1) Dissection d'Ornithodores vivants dans l'eau physiologique à $6 \%$ ou dans le Ringer ; le tégument est ouvert dorsalement, les caeca digestifs ôtés, puis les muscles sont sectionnés à leur base à l'aide d'un fragment de lame de rasoir. On obtient ainsi des muscles in toto que l'on peut cbserver au microscope entre lame et lamelle. Cette technique est surtout utile pour étudier la mobilité des filaires.

2) Dissection d'Ornithodores fixés au formol salé à $6 \%$; ce fixateur, dont la pénétration est facilitée en incisant le tégument de la tique entre les ramifications caecales, est celui qui provoque le moins de rétraction des tissus; les images que l'on observe sont très proches de celles données par les dissections in vivo, mais les muscles ainsi fixés sont moins fragiles et plus aisés à disséquer.

3) La méthode histologique normale, avec observation de coupes sériées. Dans ces conditions, les tissus sont rétractés et les mensurations sont inférieures à celles qui sont effectuées sur les préparations fraîches; certaines cavités, pratiquement virtuelles in vivo, apparaissent démesurément agrandies.

Durant les trois premiers jours qui suivent le repas infestant, les larves restent mobiles, mais elles sont moins actives que lors de leur pénétration dans les muscles. Toujours très superficielles, elles déforment le sarcolemme au gré de leurs mouvements.

Ces mouvements se ralentissent vers le $4^{*}$ jour, et à ce moment certaines larves sont immobiles, soit lovées sur elles-mêmes, soit allongées parallèlement aux fibrilles.

La croissance de la larve devient alors perceptible, mais elle est très lente ; sur coupes, les diamètres des filaires sont de $2,5 \mu$ pour la microfilaire, $4 \mu$ pour une larve du $5^{\circ}$ jour, $5 \mu$ pour une larve du $8^{e}$ jour (fig. $3 \mathrm{~A}, \mathrm{~B}, \mathrm{C}$ ).

Lors des dissections effectuées durant ce premier stade, les muscles infestés ne se distinguent des muscles sains que par la seule présence du parasite; leur organisation générale n'est pas troublée. La larve, très mince, est étroitement accolée aux myofibrilles du muscle; seule la région céphalique est coiffée par une petite vacuole en dôme au niveau de laquelle les myofibrilles sont rompues; au voisinage de cette vacuole et sur une longueur de quelques $\mu$, dans l'axe de la tête de la larve, les fibrilles perdent leur netteté et se résolvent en granules (fig. 3). L'observation des coupes confirme l'absence de toute membrane anhyste ou cellulaire s'intercalant entre 

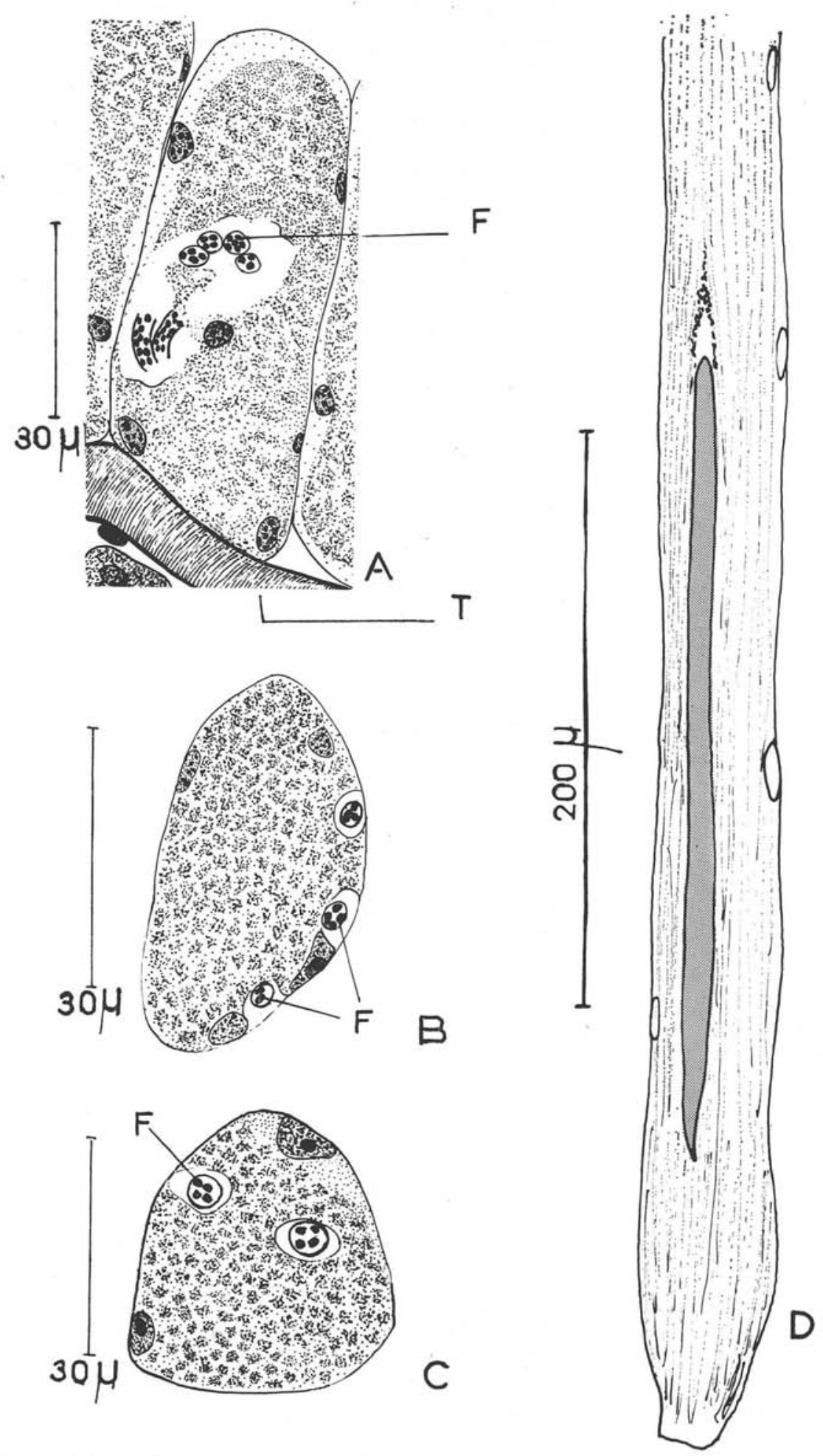

Fig. 3. - A, B, C) Coupes transversales de fibres musculaires parasitées par des larves âgées respectivement de 24 heures, 5 jours, 8 jours; D) fibre musculaire lisse parasitée par une filaire âgée de 7 jours (dissection, fixation au formol salé) 
la larve et le protoplasme du muscle ; mais tout le corps de la larve apparaît circonscrit par une vacuole (fig. $3 \mathrm{~A}, \mathrm{~B}, \mathrm{C}$ ). Celle-ci étant généralement optiquement vide, quel que soit le fixateur, et ne s'observant pas sur le vivant, nous pensons qu'il s'agit ici

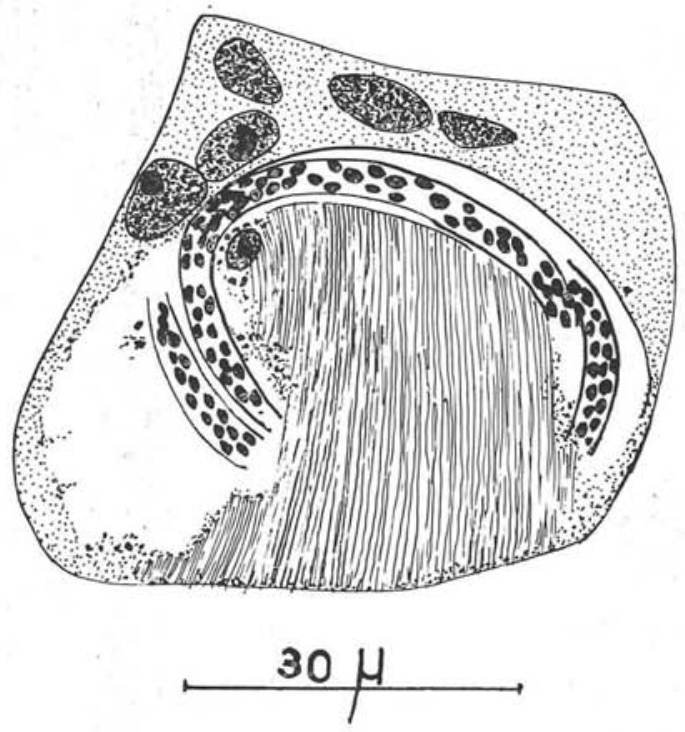

FIG. 4. - Fibre musculaire pharyngienne renfermant une microfilaire de 5 jours; les noyaux de la fibre sont un peu gonflés et les nucléoles sont volumineux

Fig. 5. - Quatre filaires de 18 jours dans une fibre lisse dorso-ventrale; la première mue est visible sur deux des larves (dissection; fixation au formol salé)

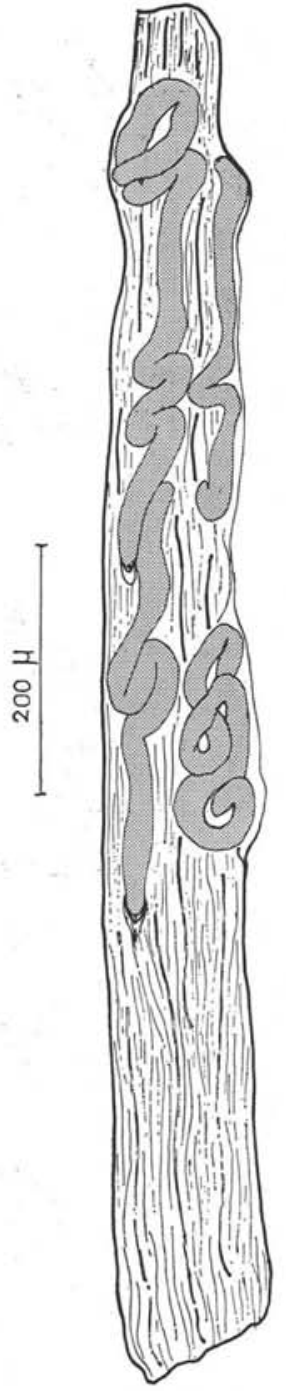

d'un artefact ; le contact est intime entre la larve et le cytoplasme de la cellule-hôte. Si les perturbations du myoplasme sont réduites au minimum, les noyaux du muscle qui sont au voisinage du parasite se modifient précocement; au $5^{\text {e }}$ jour leur nucléole est anormalement volumineux (fig. 4) et le noyau est légèrement gonflé. 
Dès le début de la vie intramusculaire, les grandes lignes du développement larvaire sont bien établies. En effet, au cours des jours suivants, la filaire agrandit son tunnel mais reste excentrique et, parfois même, elle fait encore saillie sous le sarcolemme; la vacuole et la lyse des myofibrilles sont toujours localisées en avant de la tête (fig. 6 A). Durant cette période, la larve s'organise, acquiert un tube digestif rudimentaire vers le $13^{\circ}$ jour et, dès lors, sa croissance devient rapide : $8 \mu$ de diamètre
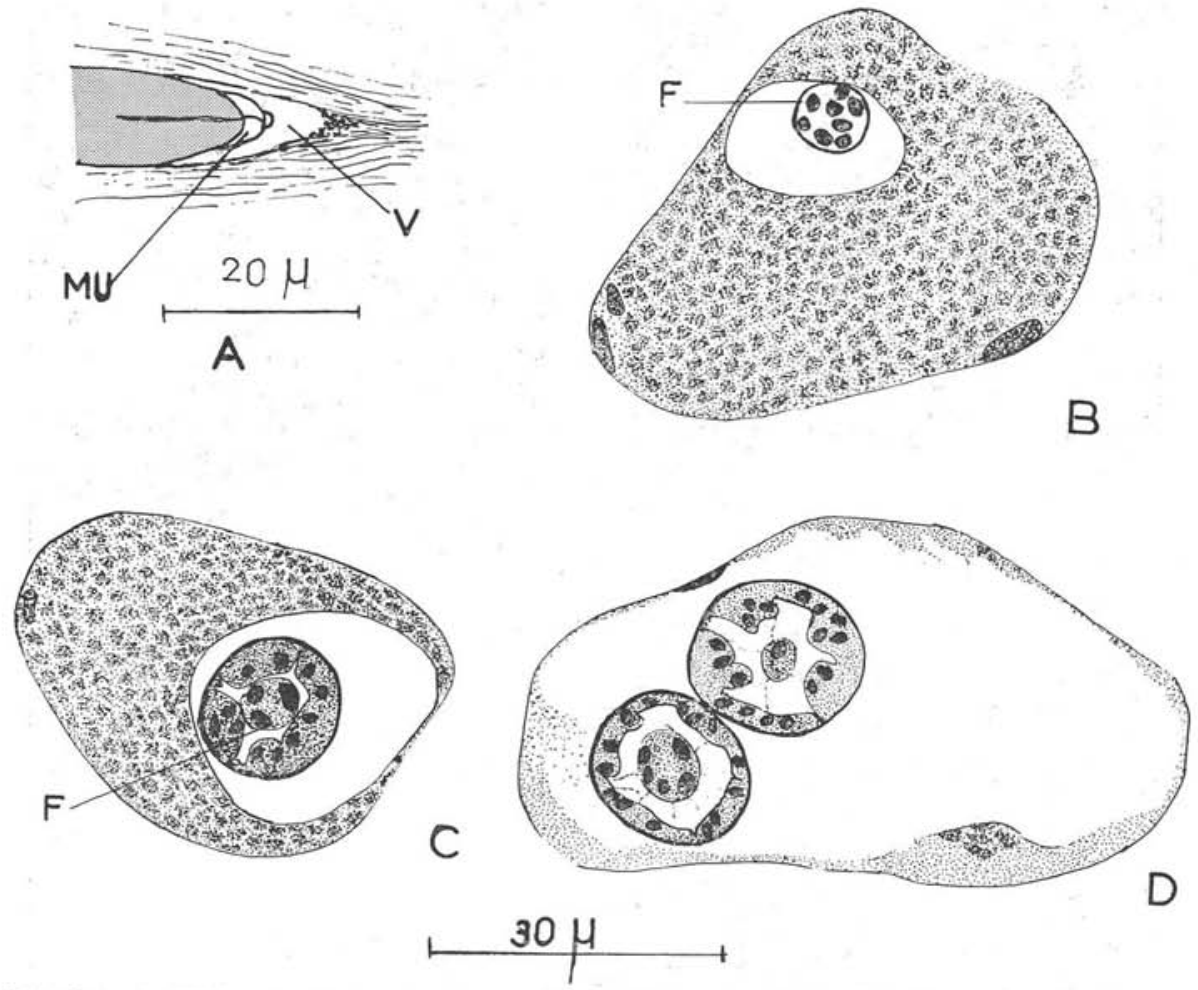

FIG. 6. - A) Filaire de 13 jours avec vacuole antérieure; la région céphalique est enfermée dans la mue I (dissection; fixation au formol salé); B, C, D) coupes transversales de fibres musculaires infestées par des larves âgées respectivement de 13 jours, 19 jours et 23 jours; en D, presque tout le myoplasme est digéré. En C et $\mathrm{D}$, le tube digestif de la larve est individualisé

le $13^{*}$ jour, $13 \mu$ le $19^{\circ}$ jour, 17 à $22 \mu$ le $23^{\text {e }}$ jour (fig. $5,6 \mathrm{~B}, \mathrm{C}, \mathrm{D}$, photo 7 ). En même temps, du glycogène s'accumule dans la larve, localisé dans certaines cellules pariétales.

Les larves occupent finalement un volume de plus en plus grand dans les fibres musculaires; celles-ci sont souvent gonflées; la destruction du myoplasme s'accentue. Les réactions des noyaux situés à proximité des filaires sont plus marquées : le nucléole est très volumineux, parfois dédoublé, et le noyau lui-même est plus gros et arrondi. Les fibres infestées ne semblent pas avoir plus de glycogène que les fibres saines. 
Les larves atteignent leur taille maximum vers le $25^{\circ}$ jour, certaines larves sont plus précoces et d'autres retardataires. Le décalage dans le développement peut être considérable ; au $25^{\circ}$ jour quelques très rares filaires n'ont pas encore de tube digestif et ont la taille de larves de 10 jours; rien dans l'aspect, ni dans la taille, ni dans la

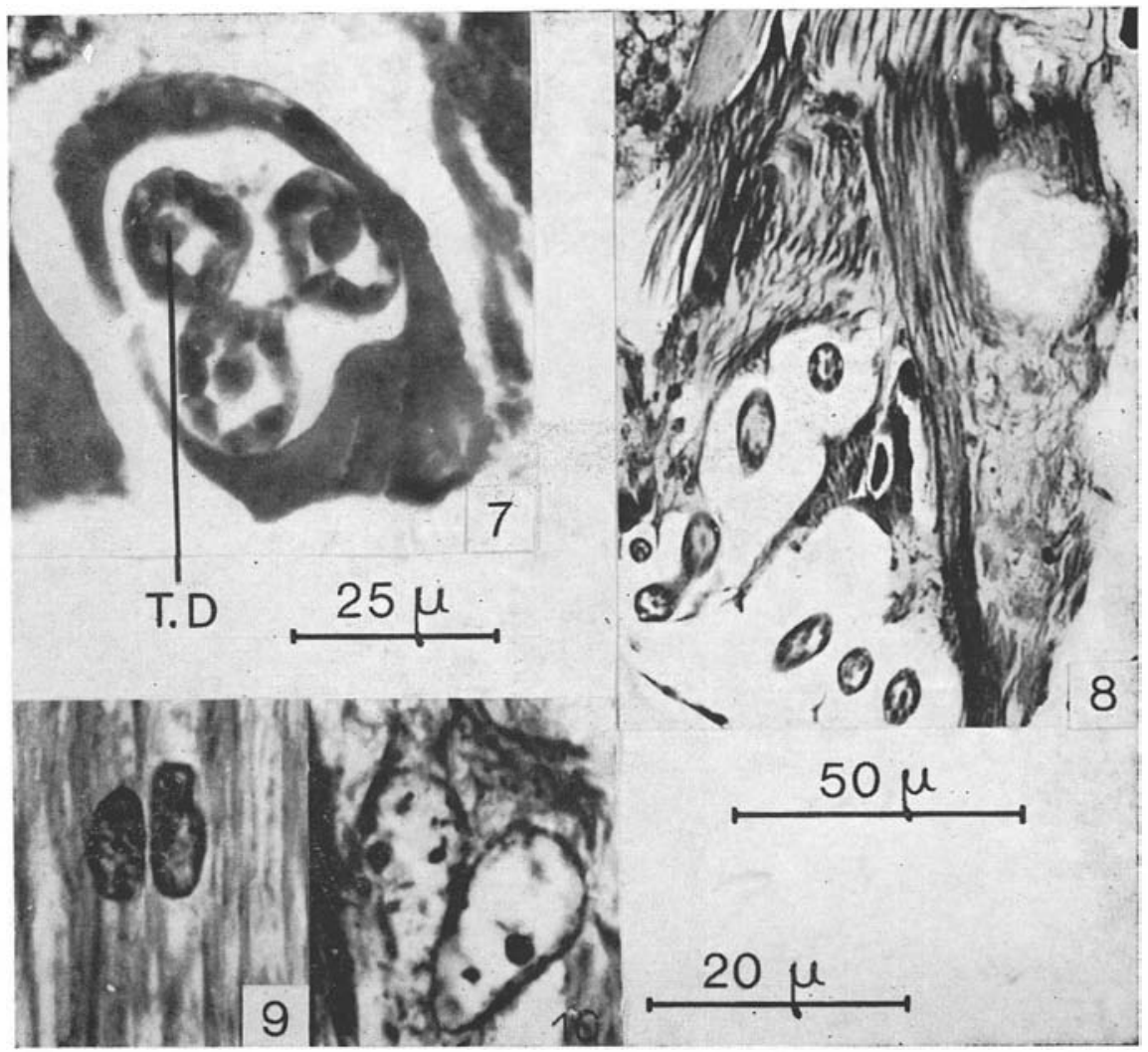

Pното 7. - Filaire âgée de 15 jours dans une fib:e musculaire (échelle : $25 \mu$ )

Рното 8. -- Musculature d'une patte chez un Ornithodore infesté depuis 25 jours (échelle: $50 \mu$ ) Photos 9 et 10. - Noyaux de fibres musculaires de pattes au même grossissement. - 9: fibre saine. -10 : fibre infestée depuis 25 jours (échelle : $20 \mu$ )

situation anatomique du muscle, ne permet de déceler les causes de ce retard; on n'observe pas davantage les prémices d'une destruction du parasite.

Finalement, les fibres infestées se présentent sous deux aspects différents; cette dualité n'est pas due à deux modes d'action possibles des larves, mais uniquement au plus ou moins grand volume de la fibre infestée: 

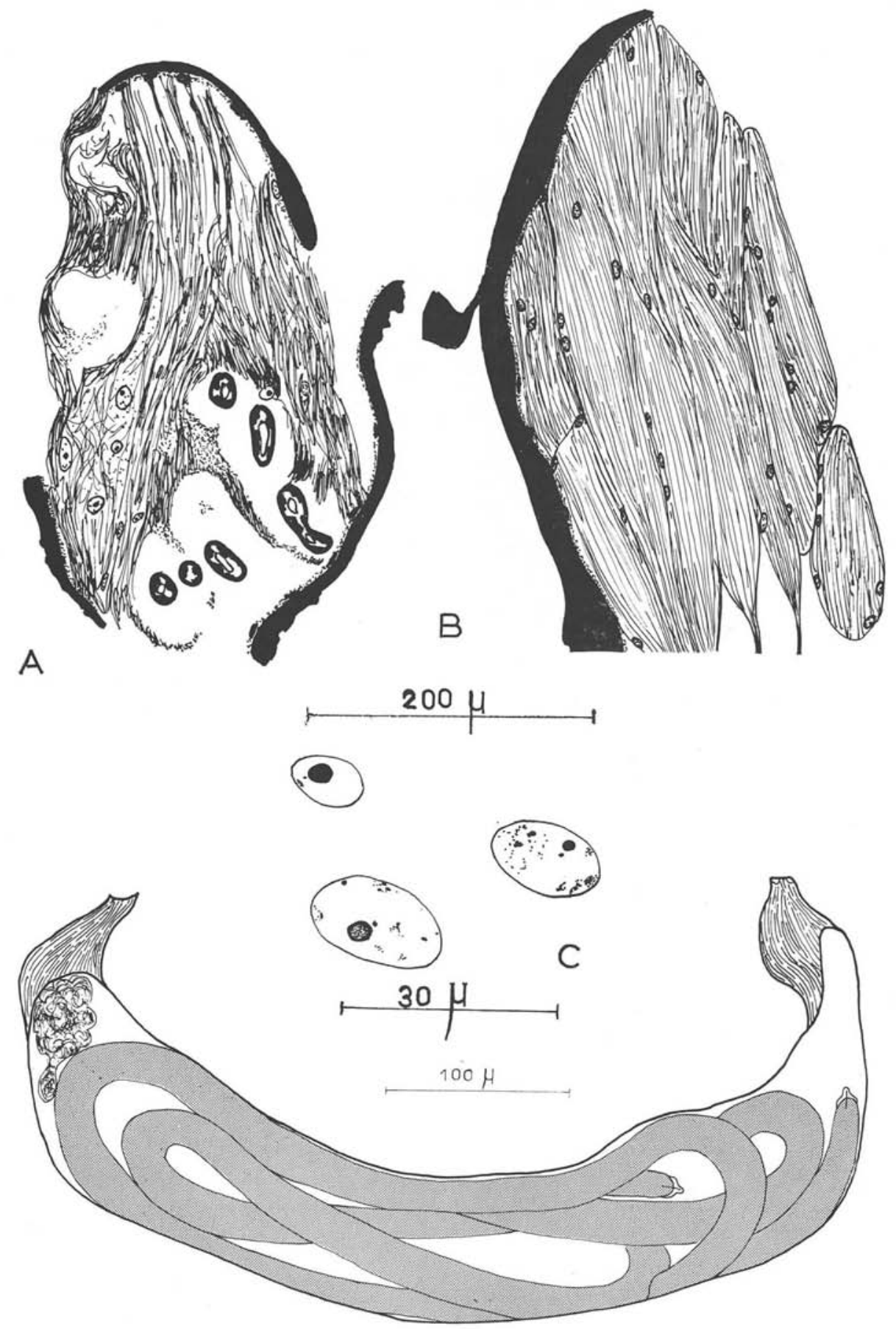

Fig. 7. - Musculature d'Ornithodore ; A) infesté depuis 26 jours ; B) sain ; C) détail de la figure A : noyaux hypertrophiés.

FIG. 8. - Deux filaires âgées de 26 jours dans une fibre musculaire presque totalement détruite ; la masse de granulations correspond probablement aux déchets des parasites (dissection) 
- Fibres musculaires de grande taille. Il s'agit ici essentiellement des fibres lisses dorso-ventrales. Très longues, elles supportent facilement l'infestation par une filaire. A part les modifications nucléaires et nucléolaires et l'interruption des myofibrilles au niveau des parasites, l'ensemble du muscle n'est pas changé; la portion non infestée de la fibre ne peut se distinguer sur coupe d'une fibre totalement saine.

- Fibres musculaires de petite taille. On peut prendre comme exemple les muscles striés des pattes ou ceux du pharynx. Dans ce cas, la fibre infestée est méconnaissable (fig. $7 \mathrm{~A}$, photo 8 ): réduite à son sarcolemme, elle forme un sac qui contient la filaire et quelques grosses granulations qui pourraient être les déchets du parasite. Le myoplasme digéré a presque totalement disparu (fig. $6 \mathrm{D}$ ); parfois quelques îlots

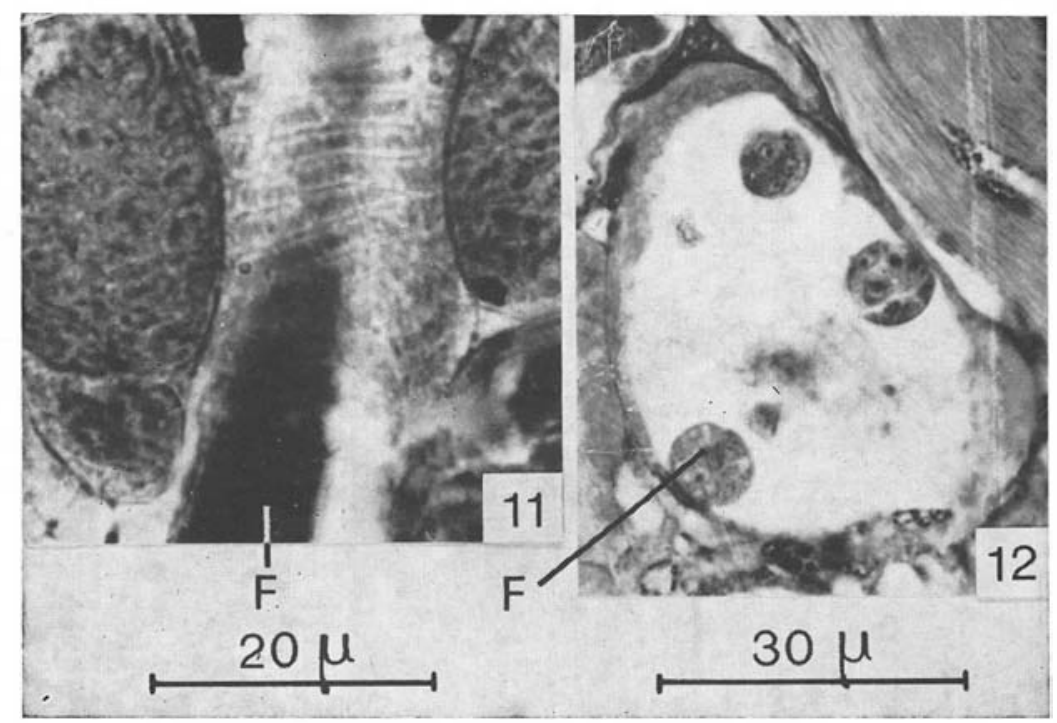

Pното 11. - Filaire âgée de 13 jours dans une petite fibre du pharynx; malgré les destructions importantes, la striation des fibrilles non atteintes persiste

Рното 12. - Acinus venimeux contenant une filaire âgée de 14 ans

de myofibrilles persistent au cœur de l'ancienne fibre. Certains noyaux sont en partie lysés par la filaire, mais ceux qui ont échappé à la destruction sont en voie de dégénérescence : énormes et vésiculeux, leur chromatine est rare et clairsemée, le nucléole est souvent vacuolaire et hypertrophié (fig. $7 \mathrm{C}$, photo 10). De tels muscles sont évidemment incapables de se contracter et ceci explique les paralysies que l'on observe chez les Ornithodores bien infestés.

Le cas de grandes fibres infestées par plusieurs filaires est assimilable à celui des petites fibres infestées par une filaire. Au cours des dissections, on voit en effet des «sacs » renfermant jusqu'à 3 ou 4 filaires lovées sur elles-mêmes (fig. 8) qui sont les restes d'une fibre musculaire. 

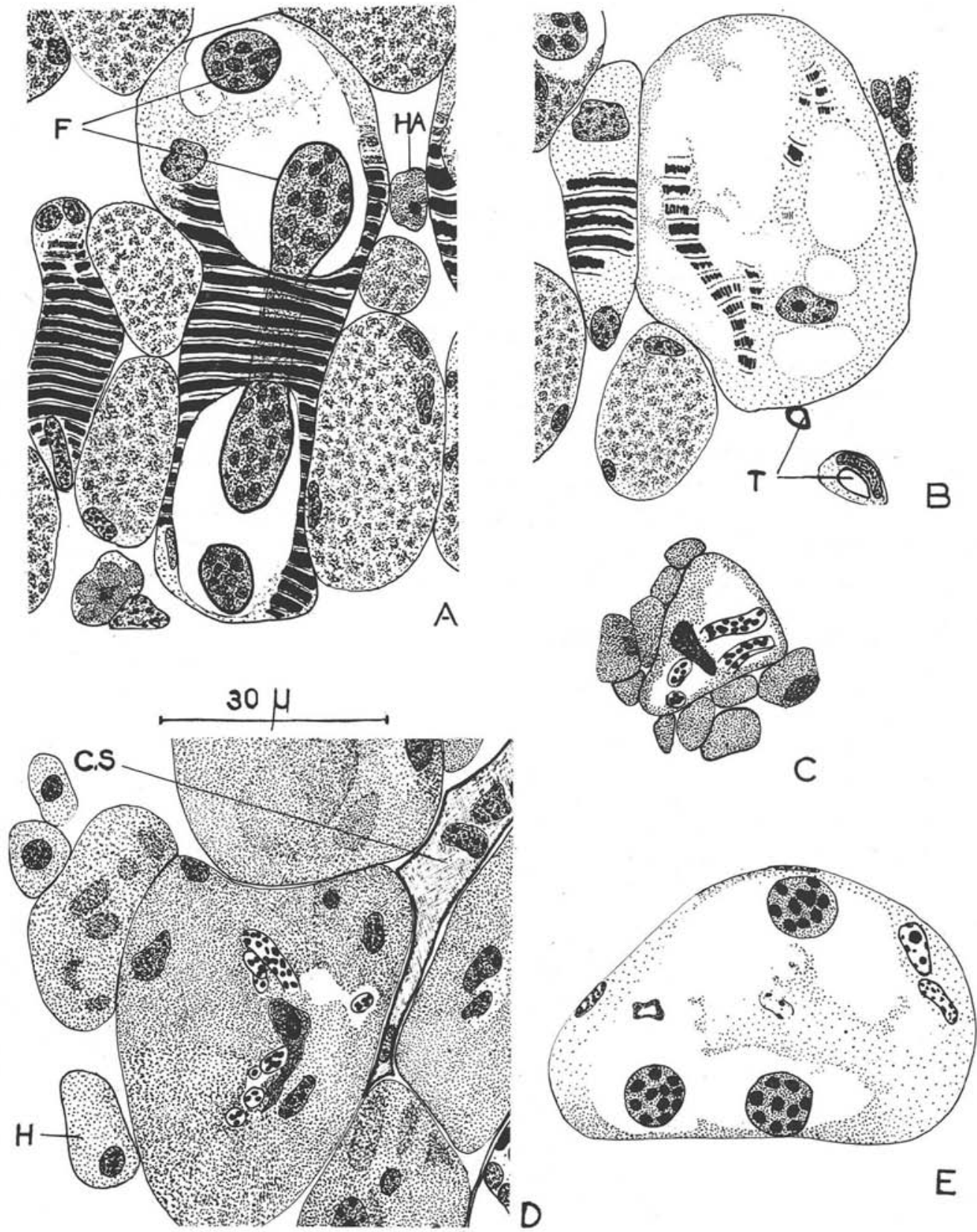

FIG. 9. - A) Filaire de 13 jours dans une fibre déjà très abîmée; B) autre fibre montrant des traces de destruction faites par une filaire qui a émigré avant le $13^{e}$ jour; C) une microfilaire de 24 heures infestant trois fibres musculaires du vagin; D) cellule venimeuse contenant une microfilaire; E) idem, avec filaire de 14 jours. On voit un noyau lysé et un «coagulum» de déchets 
Les fibres de taille intermédiaire, incomplètement digérées, sont souvent désorganisées et leurs fibrilies ne sont plus parallèles.

Nous avons observé des destructions importantes des muscles même à des stades très précoces (fig. $9 \mathrm{~A}$, photo 11 ) ; il s'agissait de petits muscles pharyngiens dont le volume a pu être évalué sur coupe à $100.000 \mu^{3}$; or, une larve, arrivée au $3^{\circ}$ stade infestant, a un volume approximatif de $400.000 \mu^{3}$. De tels muscles ne peuvent assurer à la filaire qu'un début de développement. Comme nous n'avons jamais observé de filaires libres au cours du développement, nous supposons que ces filaires, ayant évidé un muscle (photo 14), attaquent le muscle contigu. Bien que le sarcolemme semble offrir une résistance particulière aux diastases de la filaire, cette hypothèse paraît très probable : ainsi, dans les muscles du vagin qui sont particulièrement petits $(8$ à $10 \mu$ de diamètre), une larve âgée d'un jour a été observée au moment où elle occupait trois fibres contiguës (fig. $9 \mathrm{C}$ ).

Nous avons étudié jusqu'à présent le développement des filaires dans les muscles ; c'est en effet le mode de développement le plus normal, mais nous avons vu que les microfilaires pouvaient pénétrer dans les cellules venimeuses. Elles s'y développent normalement, à la même vitesse que dans les muscles, et les effets du parasite sont les mêmes : destruction progressive du cytoplasme, gonflement de la cellule-hôte, apparition de gros nucléoles dans les noyaux (fig. $9 \mathrm{E}$, photo 12).

En conclusion, la larve de Dipetalonema viteae est capable de se développer dans deux types d'organes: les muscles et les acini venimeux. Dans les deux cas, la larve s'accroît en 25 jours environ; elle se nourrit aux dépens du protoplasme de la cellule parasitée; la présence d'une petite vacuole précéphalique semble indiquer que la région buccale émet des enzymes protéolytiques qui prédigèrent le protoplasme; mais ces enzymes diffusent peu et ont une action très localisée comme le prouve la destruction très progressive des fibrilles.

Si les grandes cellules supportent très bien l'infestation, les plus petites finissent par être détruites; seule persiste la membrane cytoplasmique qui sert d'enveloppe au parasite.

L'organe infesté réagit: l'hypertrophie locale des noyaux et des nucléoles pourrait indiquer une augmentation de son métabolisme; l'exagération de cette hypertrophie détermine finalement la mort et la lyse des noyaux.

Donc, si la larve de Dipetalonema viteae peut détruire totalement certains muscles de petite taille, dans un muscle suffisamment grand, les destructions qu'elle effectue sont minimes, très localisées, et correspondent seulement à ses besoins nutritifs. La cellule infestée, de son côté, est parfaitement réceptive; les larves qui s'y abritent arriveront à maturité. Parasite et cellule-hôte sont bien adaptés l'un à l'autre. 


\section{CHAPITRE IV}

\section{La libération cellulaire}

\section{Effraction de la cellule-hôte.}

Vers la fin de leur développement les filaires redeviennent peu à peu mobiles. Cette reprise d'activité correspond à la période de libération des larves.

Des Ornithodores disséqués le $25^{\circ}$ jour montrent à la fois des larves libres et bien mobiles, des larves qui s'échappent des muscles et d'autres enfin qui remuent plus ou moins violemment dans les fibres qui les emprisonnent. Sous la poussée des filaires, la paroi cytoplasmique est distendue et finit par se rompre; la filaire se dégage ensuite plus ou moins rapidement; elle laisse derrière elle l'ancienne cellule-hôte (fig. $10 \mathrm{~A}$ ).

Les filaires qui se libèrent ainsi sont des larves du troisième stade, facilement reconnaissables à leur extrémité caudale arrondie, munie de deux languettes; plus rarement, ce sont des larves qui effectuent leur deuxième mue, et parfois des larves de la fin du deuxième stade. Ces dernières sont en général assez peu mobiles, et sont sans doute libérées artificiellement par des lésions faites sur les muscles au cours de la dissection.

$\mathrm{Au} 30^{\circ}$ jour, à quelques exceptions près, toutes les filaires ont abandonné leur cellule-hôte et sont totalement libres dans la cavité générale, baignant dans l'haemolymphe de l'Ornithodore.

\section{Répartition des larves libres.}

Pour disséquer un Ornithodore, le tégument est en général ouvert à l'extrémité postérieure ; par l'échancrure ainsi pratiquée, des filaires s'échappent immédiatement ; puis la tique, une fois totalement ouverte, montre un fourmillement de larves, insinuées partout entre tous les organes. Ces premières observations indiquent que les filaires peuvent occuper indifféremment toutes les parties du corps de l'Ornithodore.

Des coupes longitudinales de Tiques ébouillantées à l'alcool butylique, effectuées à main levée, permettent de voir in situ les filaires: parfois étirées entre les organes, elles sont le plus souvent lovées sur elles-mêmes ou enchevêtrées en pelotons.

L'étude des coupes histologiques confirme la répartition quelconque des filaires et l'absence d'une orientation de leur corps; on trouve des sections de filaires dans l'espace sanguin ménagé entre les caeca digestifs et l'hypoderme, entre les caeca, près des muscles des pattes, entre les glandes génitales et leurs annexes, et près de la vésicule excrétrice.

Mais, d'une part, il y a très rarement des filaires entre les muscles pharyngiens, même au cas où, manifestement, ces muscles ont été infestés; d'autre part, il y a 
souvent une densité maximum de sections de filaires dans les régions suivantes: audessus des chélicères, dans l'épistome, autour du cerveau et autour de l'œsophage, c'est-à-dire en arrière et au-dessous du cône buccal.

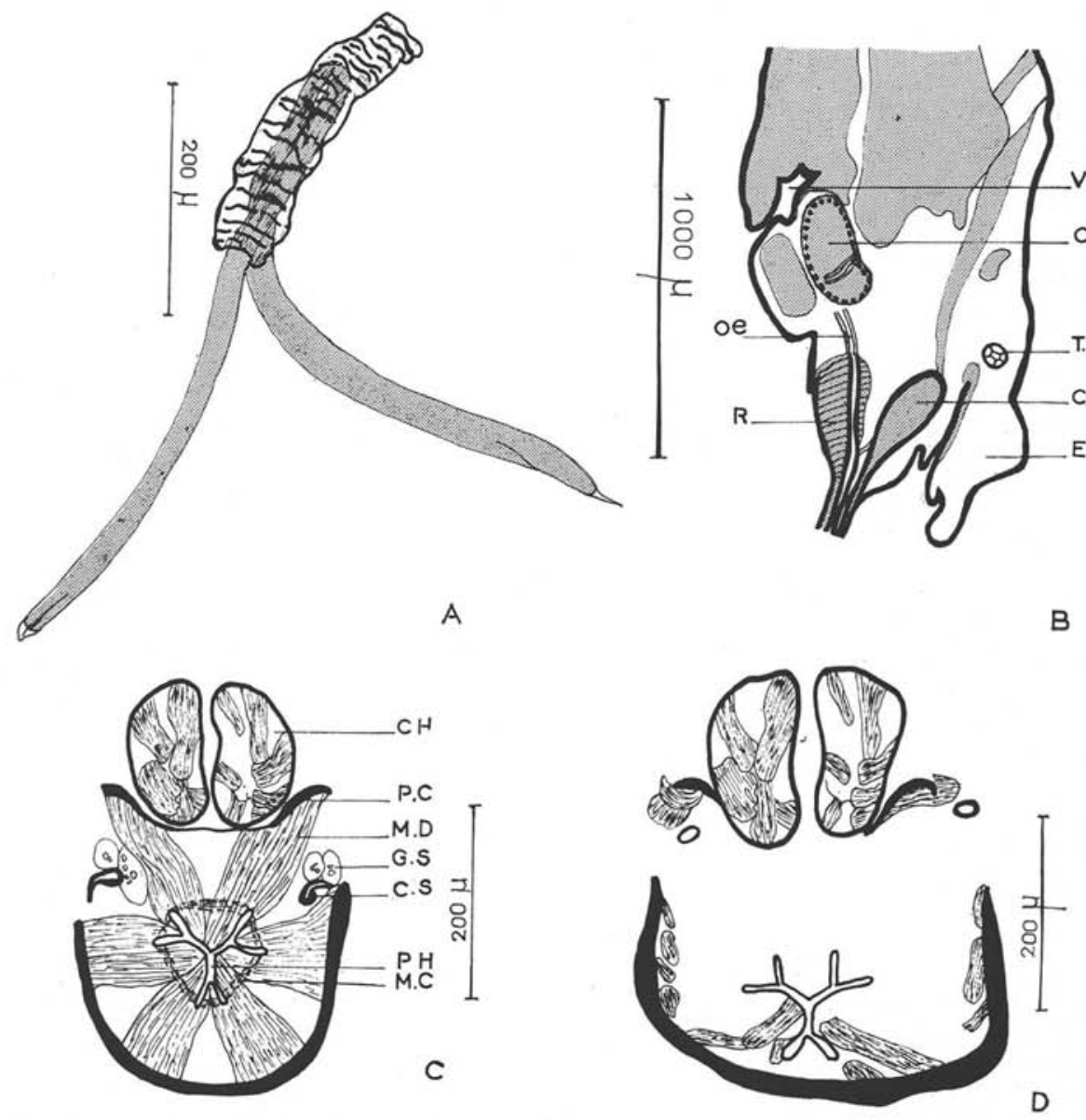

Fig. 10. - A) Une filaire effectuant la mue II se libère d'une fibre musculaire évidée; B) coupe sagittale schématique de la moitié antérieure d'un Ornithodore montrant l'espace périøesophagien et le vide sus-chélicérien; C et D) coupe transversale du pharynx d'un Ornithodore sain (C) et d'un Ornithodore infesté dont la musculature est détruite (66 jours)

Pour expliquer l'existence d'une zone privilégiée où se concentre une partie des filaires, il est nécessaire d'indiquer brièvement l'anatomie d'un Ornithodore. Chez un adulte, mâle ou femelle, on peut opposer deux régions : une région postérieure à l'orifice génital, constituée par une masse volumineuse et compacte d'organes génitaux, de caeca digestifs, et d'une vésicule excrétrice qui est de plus en plus envahissante au 
cours de la digestion; une région antérieure au pore génital où sont aisément logés le cerveau, l'œsophage étroit, les caeca digestifs et, tout en avant, le pharynx et la musculature du capitulum. Autour du cerveau et de l'œsophage, au-dessus des chélicères subsistent toujours des espaces assez importants, où abondent les haemocytes. Le volume de ces cavités peut augmenter considérablement chez un animal à jeun par régression des caeca qui sont presque vides: le caecum occupant normalement l'épistome et celui qui est au-dessus des chélicères peuvent ainsi disparaître complètement (fig. $10 \mathrm{~B}$ ). On conçoit que, dans ces cavités naturelles, il puisse y avoir un plus grand nombre de filaires que dans des zones où les organes sont si étroitement appliqués les uns aux autres qu'ils ne laissent plus d'espaces entre eux.

Ceci est confirmé par les observations suivantes: d'une part, un comptage de filaires a été effectué chez deux spécimens; l'un présente une forte rétraction des
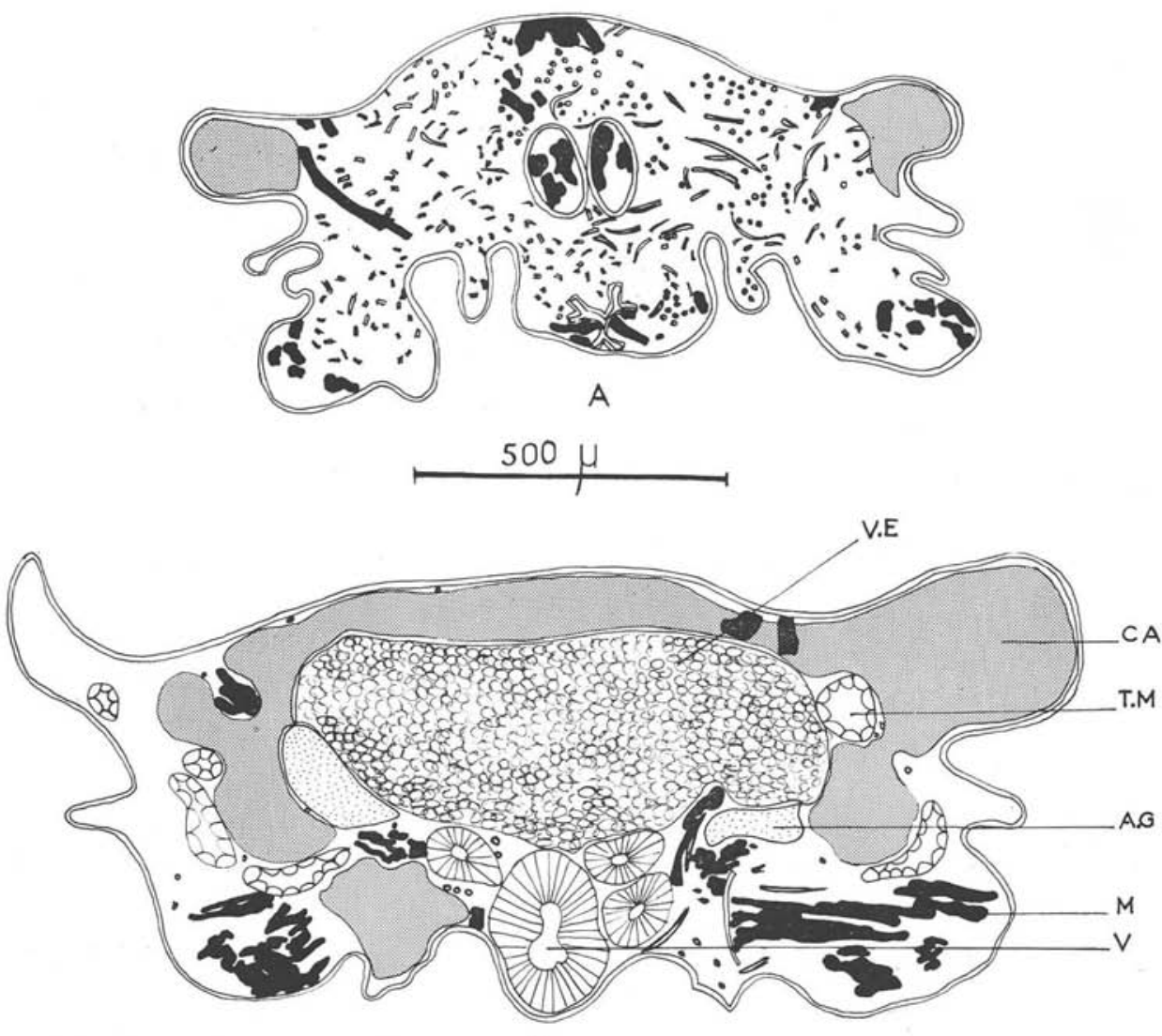

B

Fig. 11. - Coupe transversale d'un Ornithodore contenant des filaires libres: A) au niveau du pharynx; B) au niveau du vagin 
caeca, tandis que l'autre a conservé le caecum de l'épistome et le caecum sus-chélicérien. Chez le premier, on compte 177 sections de filaires à la base du capitulum, contre 89 sections un peu en arrière du pore génital (fig. 11) ; chez le second (fig. 12),
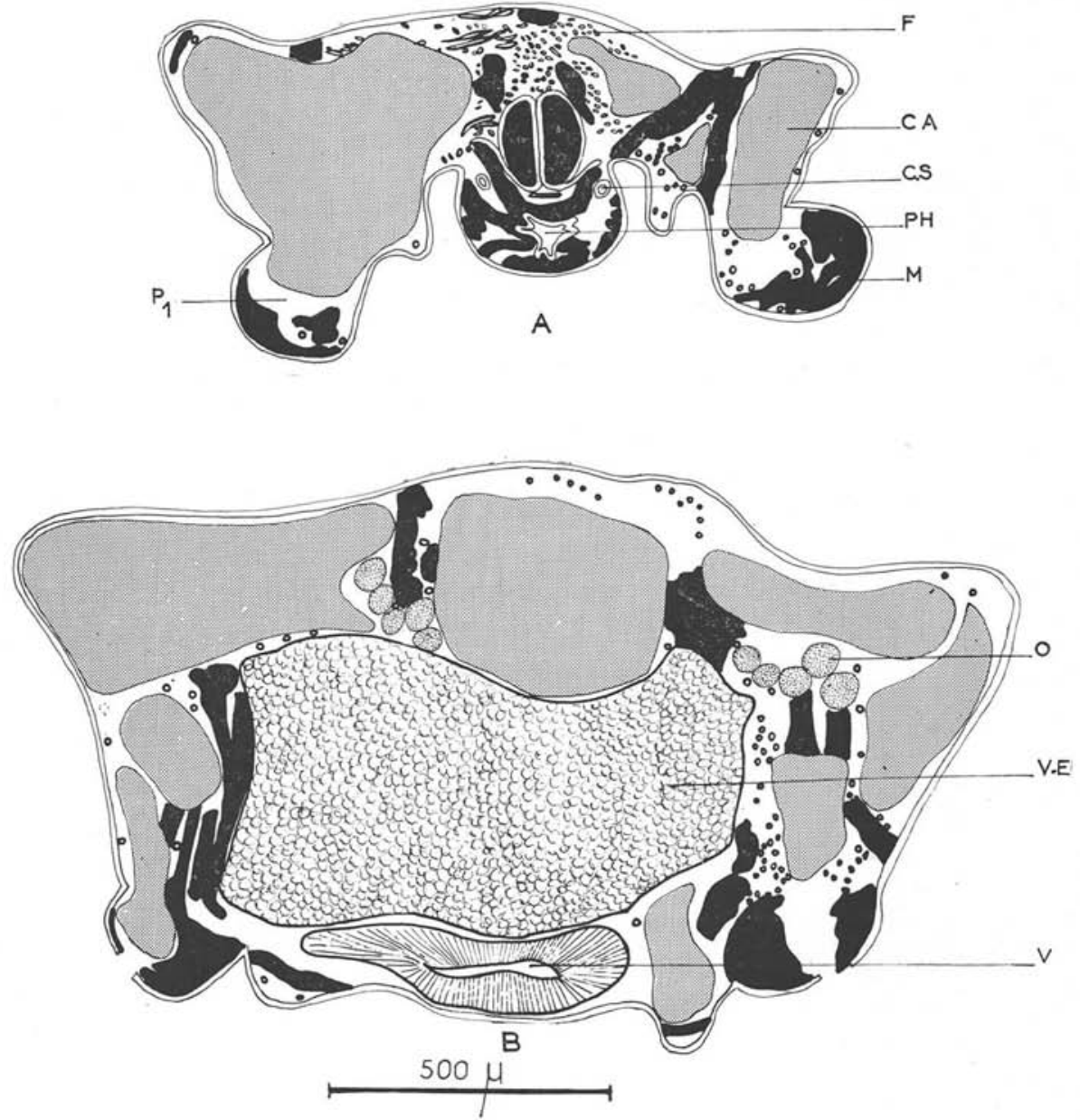

FIG. 12. - Coupes homologues de $11 \mathrm{~A}$ et de $11 \mathrm{~B}$ chez un Ornithodore montrant une moindre réduction des caeca dans la région antérieure. En A, les filaires se localisent essentiellement dans le vide sus-chélicérien

six sections sur la coupe antérieure et autant au niveau des glandes génitales, le maximum de 11 sections étant obtenu pour la coupe qui passe au niveau du cerveau.

D'autre part, dans ces cavités, on observe souvent des spermatophores qui, pourtant, sont immobiles, et qui ont pu être entraînés par la circulation sanguine de la Tique. 


\section{Evolution des muscles anciennement parasités.}

En se libérant, les filaires abandonnent les fibres musculaires qui sont digérées à des degrés divers. Suivant l'importance des destructions qu'elles ont subies, elles vont évoluer selon les modes suivants:

- Les muscles réduits à l'état de sacs sarcolemmiques disparaissent. Cette destruction totale est facilement mise en évidence en comparant des coupes homologues d'Ornithodores sains et d'Ornithodores infestés, depuis 60 jours par exemple. On choisit de préférence des coupes effectuées au niveau du pharynx, car l'anatomie des muscles dilatateurs ou constricteurs se repère aisément (fig. $10 \mathrm{C}$ et $\mathrm{D}$; photos 6 et 13).

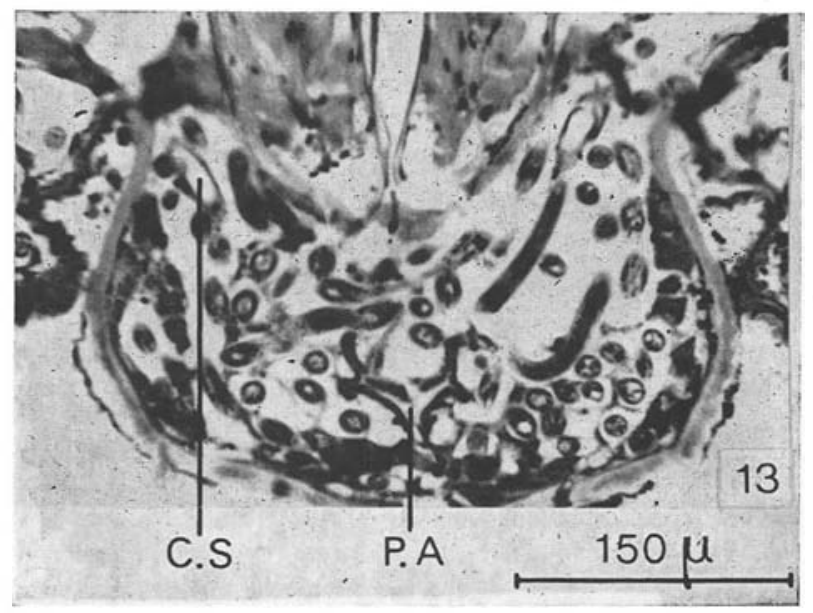

Pното 13. - Ornithodore très fortement infesté dans lequel la musculature pharyngienne est détruite

Deux ou trois jours après la libération des filaires, des fragments de membranes sarcolemmiques et des résidus à noyaux picnotiques occupent la cavité générale de l'Ornithodore. Mais, une vingtaine de jours plus tard, ces résidus ont totalement disparu. Il est probable que les haemocytes interviennent activement au cours de ce «nettoyage »; l'observation d'une fibre, évidée par le parasite, et occupée par un haemocyte, suggère une destruction par phagocytose (fig. 13 B; photo 14).

- Les muscles incomplètement digérés se réparent et survivent. Dans les grandes fibres, la destruction provoquée par les filaires étant très localisée, la nécrose ne gagne pas toute la fibre; dès le $27^{e}$ jour, il est presque impossible de reconnaître une fibre anciennement infestée, sauf si la filaire a laissé son empreinte dans le myoplasme (fig. $13 \mathrm{~F}$ ).

Dans les fibres plus atteintes, les effets du parasitisme persistent plus longtemps. Quatre à cinq jours après la libération des filaires, de telles fibres présentent encore une portion nécrosée à noyaux irréguliers et piquetés de chromatine, sans myoplasme 
et à sarcolemme plissé ; en suivant les coupes sériées, on passe insensiblement à la portion du muscle restée saine (fig. $13 \mathrm{C}, \mathrm{D}, \mathrm{E}$ ). A cette même date, certains muscles ont un nombre particulièrement élevé de noyaux; cette observation fait songer à la possibilité d'une régénération, mais nous n'avons pas observé de noyaux en division (fig. $13 \mathrm{~A}$ ) ; de plus, tous les muscles ne régénèrent pas, puisque, soixante jours après
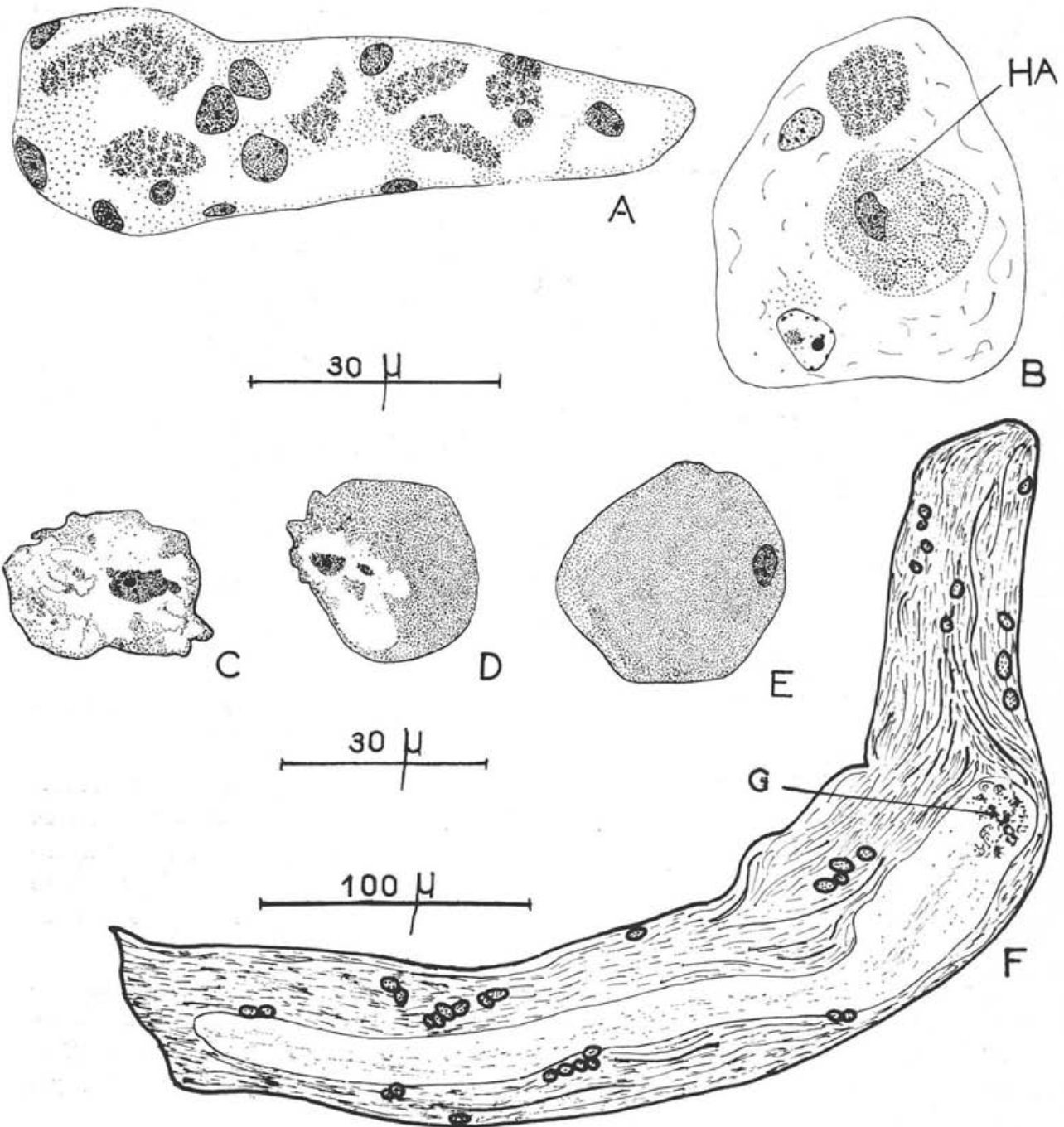

FIG. 13. - Fibres anciennement parasitées: A) avec nombreux noyaux, en régénération; B) envahie par un haemocyte granuleux; C, D, E) la même fibre à différents niveaux montrant que la lésion provoquée par la filaire est très localisée (4 jours après libération des filaires); F) avec véritable moulage du parasite et persistance du coagulum de déchets (dissection; $27^{\circ}$ jour) 
l'infestation, certains muscles anciennement infestés sont réduits au cinquième de leur volume normal, tout en paraissant sains (cas des muscles dilatateurs dorsaux du pharynx) (fig. $10 \mathrm{D})$.

En conclusion, les filaires quittent la cellule-hôte au début du troisième stade larvaire ; très mobiles, elles se libèrent par effraction de la membrane cytoplasmique qui les emprisonne. Il est apparu dans un chapitre précédent que les filaires infestaient indifféremment tous les muscles; ici encore, elles se répartissent au hasard dans la cavité générale; mobiles, elles peuvent se déplacer et ont tendance à se grouper dans les espaces sanguins les plus vastes, c'est-à-dire dans la région du cerveau et en arrière des chélicères. Elles ne présentent aucune direction privilégiée.

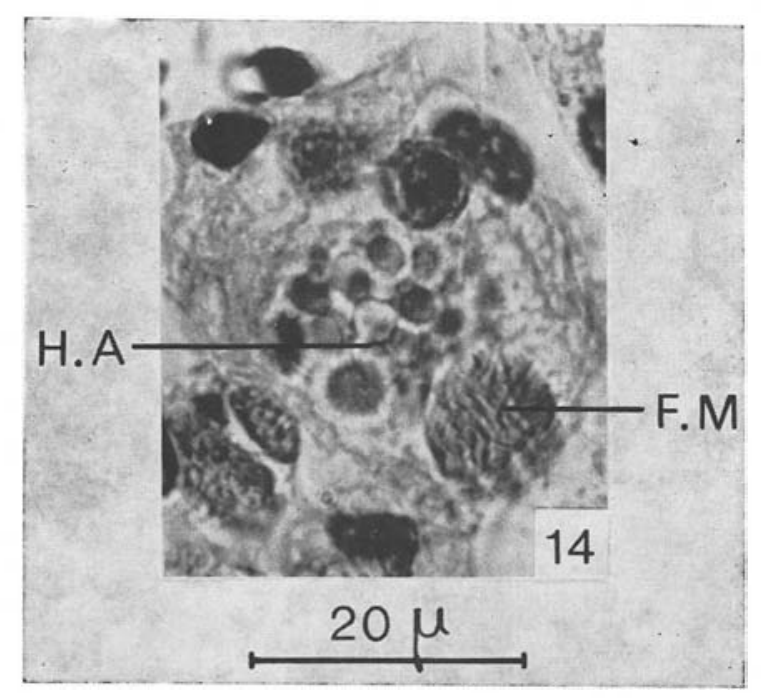

Рното 14. - Fibre musculaire anciennement infestée, envahie par un haemocyte granuleux

Les muscles, suivant le degré de destruction qu'ils ont atteint, disparaissent totalement et sont nettoyés par les haemocytes, ou persistent à l'état de moignons cicatrisés, ou, étant relativement peu infestés par rapport à leur volume, ne présentent alors que des lésions difficilement décelables.

La question d'une régénération possible du muscle n'est pas définitivement résolue. 


\section{CHAPITRE V}

\section{La transmission}

En faisant piquer des Ornithodores infestés sur un Mérion, A.-G. Chabaud en 1954 avait observé une fois, sur une Tique qu'il avait prélevée pendant le repas, six filaires qui sortaient des pièces buccales.

Nous allons chercher à préciser le mécanisme de la transmission de Dipetalonema viteae.

\section{Technique :}

Les Ornithodores contenant des larves mûres âgées de 30 à 70 jours sont placés sur des Hamsters, des Mérions ou des Cobayes. Les Ornithodores sont prélevés un à un au cours du repas en notant pour chacun la durée de la piqûre. Chaque Ornithodore ainsi détaché de la peau est plongé immédiatement dans l'alcool butylique bouillant; il est ensuite inclus selon les techniques histologiques normales, ou taillé à main levée pour obtenir des coupes sagittales épaisses qui permettent d'observer les filaires in toto après éclaircissement au lactophénol.

\section{Migration des larves infestantes vers les pièces buccales.}

Sur les Tiques prélevées pendant le repas, les filaires n'ont plus une répartition quelconque conditionnée seulement par l'anatomie des cavités de l'hôte intermédiaire. Il y a un déplacement des larves vers le cône buccal de l'Ornithodore.

En utilisant quelques Tiques où le phénomène est facilement appréciable grâce à une infestation massive, nous avons compté les sections de filaires sur des coupes homologues.

Chez un Ornithodore n'ayant pas piqué : 177 sections à la base du capitulum, 89 sections au niveau du vagin, un peu en arrière de l'orifice génital.

Chez deux Ornithodores pris pendant la piqûre : a) 377 sections à la base du capitulum, 25 sections au niveau du vagin ; b) 329 sections à la base du capitulum, $O$ section au niveau du vagin.

Généralement il n'y a presque plus de filaires dans les $2 / 3$ postérieurs du corps. Elles sont nombreuses autour du cerveau, de l'œsophage et à la base du rostre entre les chélicères et les canaux salivaires, mais elles sont surtout rassemblées dans la partie antérieure du cône buccal. Elles occupent l'emplacement des anciens muscles, s'ils ont été détruits, ou s'infiltrent entre les faisceaux musculaires, s'ils sont restés intacts; enfin et surtout elles sont particulièrement abondantes entre la paroi dorsale du pharynx et le plateau cuticulaire hypochélicérien (photo 17) ; chez un Ornithodore faiblement infesté, c'est même souvent la seule région du rostre qui contienne des filaires. 
On peut par l'examen des coupes se rendre compte que, pendant la piqûre de l'Ornithodore, les filaires qui étaient éparpillées dans la moitié postérieure effectuent une migration postéro-antérieure en empruntant comme voies de passage les cavités

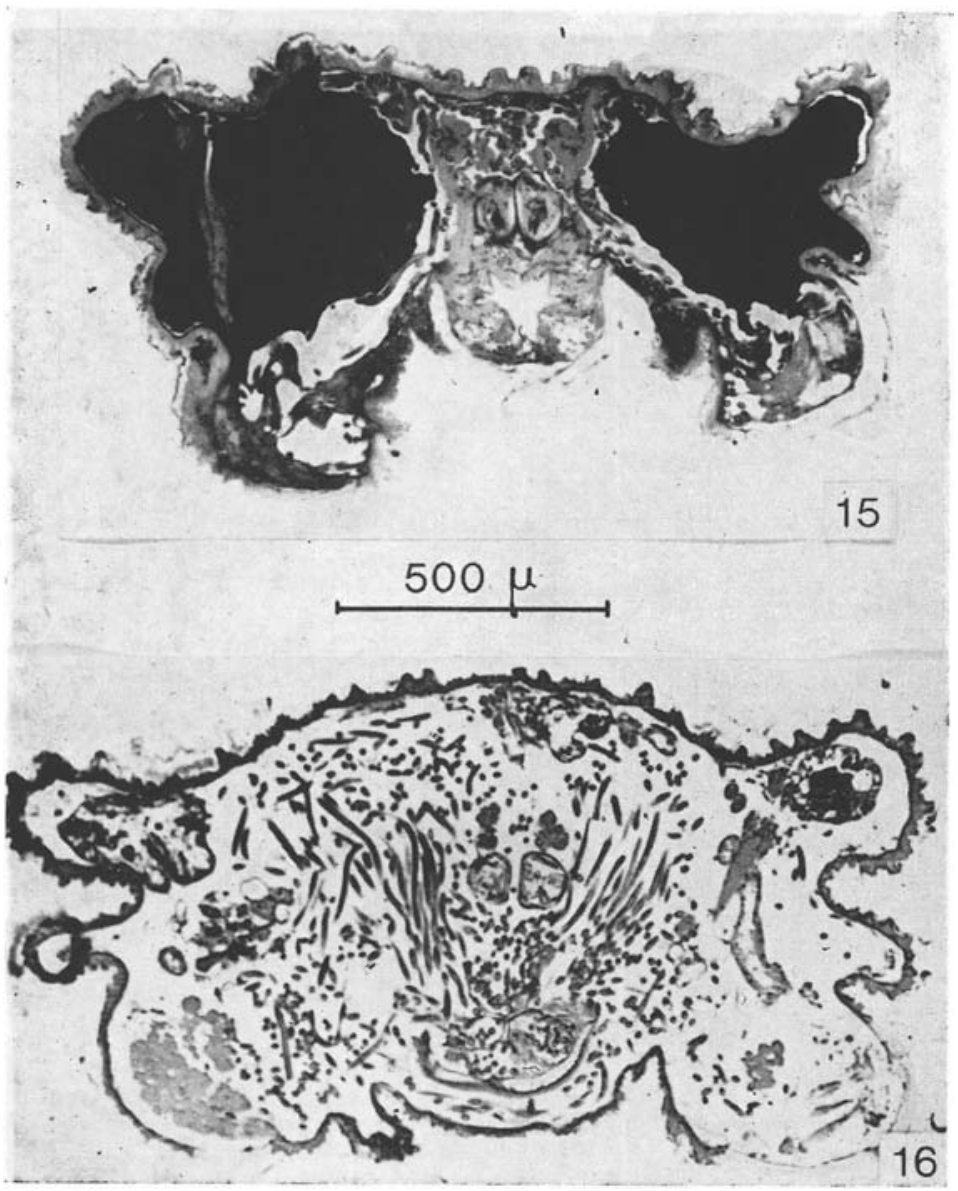

Pното 15. - Avant le repas: Filaires dans le vide sus-chélicérien

Рното 16. - Cinq minutes après la piqûre, les filaires descendent vers le pharynx (figure en éventail)

péricérébrale et périœsophagienne ; tandis que les larves qui étaient massées dans la cavité sus-chélicèrienne (photo 15) effectuent une migration dorso-ventrale en se glissant entre les chélicères et la paroi dorsale du pharynx, parallèlement aux deux canaux salivaires, ce qui donne un aspect en éventail très caractéristique (photo 16). 
Au cours de leurs déplacements, les filaires ont généralement la tête dirigée vers l'avant, et le corps plus ou moins paral'èle à l'axe du mouvement; dans la région dorsale du pharynx, elles sont au contraire perpendiculaires à l'axe du corps.

La migration est un phénomène très rapide: elle est déjà amorcée sur des Ornithodores prélevés $30^{\prime \prime}$ ou $1^{\prime}$ après la piqûre et est très nette sur des spécimens qui piquent depuis 5 minutes. Ces spécimens n'ont généralement pas encore eu le temps de prélever du sang: les caeca ne renferment en effet aucun leucocyte fraîchement

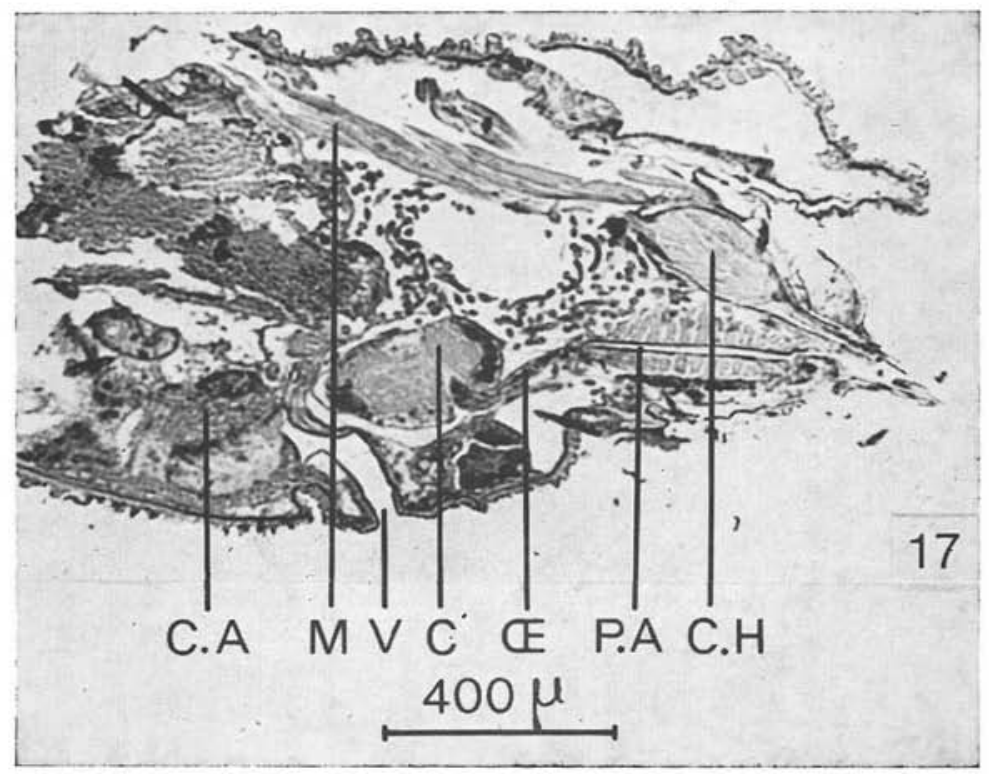

Рното 17. - Les filaires s'infiltrent entre les chélicères et le pharynx pendant le repas

ingéré. La migration paraît donc être indépendante du repas de sang proprement dit mais est uniquement liée à la piqûre.

\section{Sortie des larves infestantes par les pièces buccales.}

Pour comprendre le mécanisme de la sortie des larves mûres du troisième stade, il est nécessaire de décrire brièvement le rostre d'O. tartakowskyi et de donner un aperçu des fonctions des pièces buccales.

ANATOMIE DU ROSTRE ET HYPOTHÈSES SUR LE FONCTIONNEMENT DES PIÈCES BUCCALES

La structure du rostre n'a pas encore été décrite chez cette espèce ; elle est assez proche de celle d'O. moubata étudiée par Bertram en 1939. Pour nos descriptions, afin 

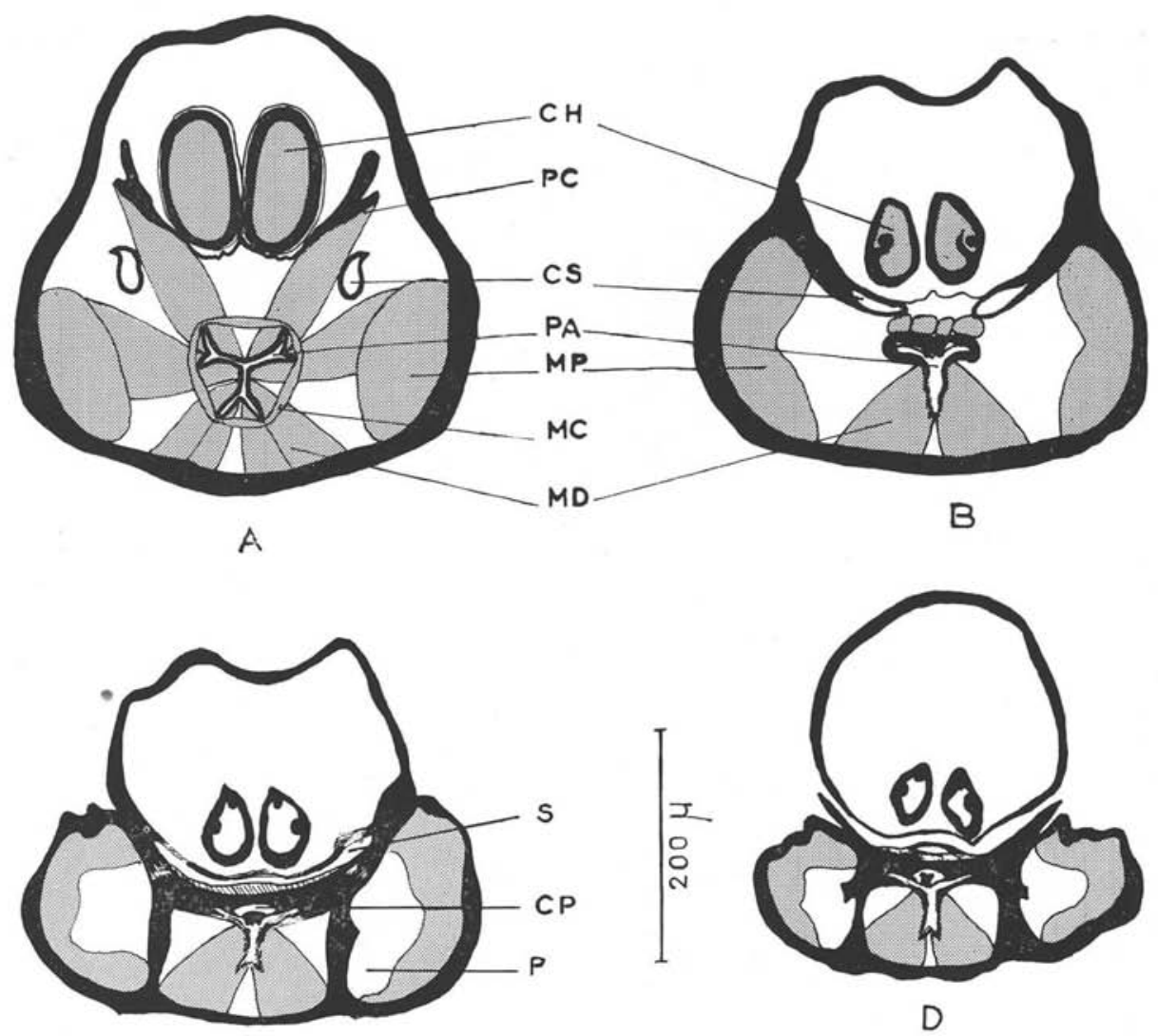

C
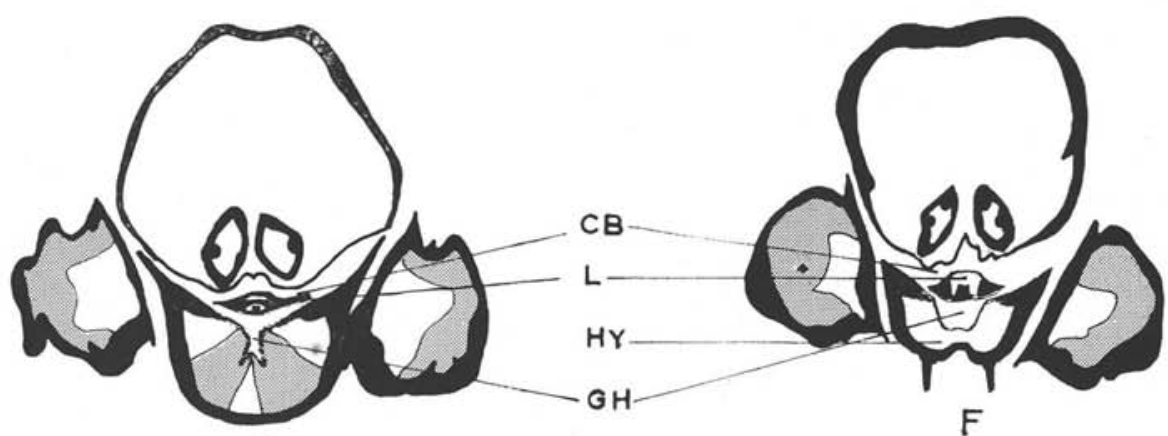

E

FIG. 14. - Structure du rostre. Coupes transversales de la partie proximale vers la partie distale : A) au milieu du pharynx; B) fusion des canaux salivaires avec la plaque sous-chélicérienne; C) au niveau du salivarium; à ce niveau, la tige ventrale à trois arêtes fonctionne comme un clapet ; D) salivarium ouvert à l'extérieur; E) orifice pharyngien; le labre est individualisé; F) Cavité buccale limitée par la gaine des chélicères et la languette hypostomienne 
de donner des dimensions homogènes, nous avons pris comme exemple une Tique femelle adulte coupée transversalement.

Le rostre, de forme conique, peut être divisé en deux parties : une moitié dorsale constituée par les chélicères et leur système de gaines, et une moitié ventrale comprenant le pharynx et l'hypostome, ou cône buccal, et les pédipalpes. La lame chitineuse sous-chélicérienne, qui sert d'insertion aux muscles dilatateurs dorsaux du pharynx, marque la séparation entre ces deux régions (fig. 14 A ; fig. 15 ; photo 6).

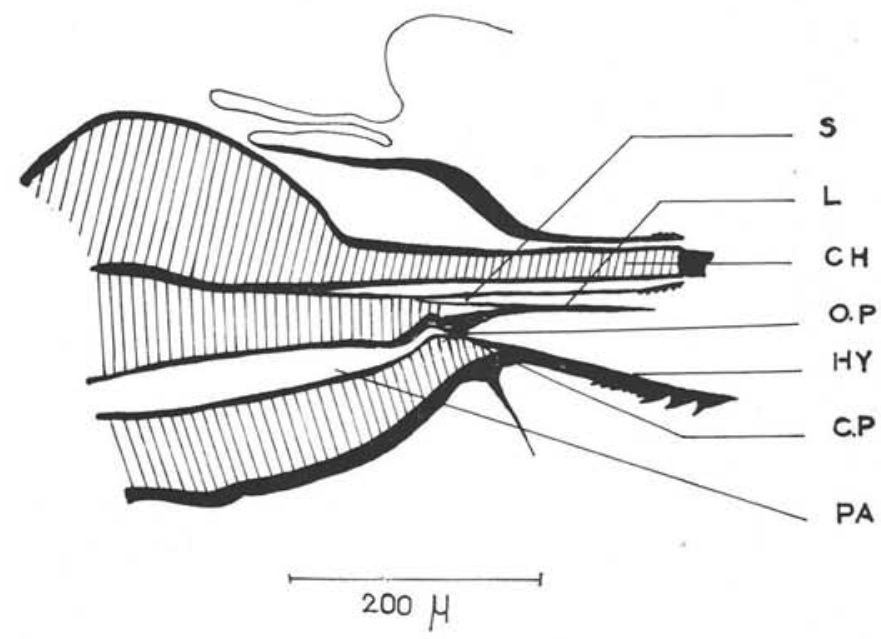

Fig. 15. - Coupe schématique sagittale du rostre d'Ornithodoros tartakowskyi

Les deux canaux salivaires à paroi chitineuse pénètrent séparément dans le cône buccal en se dirigeant l'un vers l'autre ; vers l'avant, ils se soudent à la plaque souschélicérienne en s'aplatissant et en s'élargissant (fig. $14 \mathrm{~B}$ ) ; les deux conduits finissent par fusionner à $250 \mu$ de l'apex de l'hypostome, formant ainsi le salivarium, conduit plat, large de $200 \mu$; il est limité dorsalement par la gaine des chélicères et, ventralement, par une membrane chitineuse parallèle au toit du pharynx; ces parois sont minces et souples (fig. 14 C). Le salivarium se continue sur une longueur de $22 \mu$, puis il s'ouvre latéralement à l'extérieur (fig. $14 \mathrm{D}$; photo 20).

Le pharynx, à la base du rostre, a une section en $\mathrm{Y}$ dont chaque branche est bifurquée à l'extrémité (fig. $14 \mathrm{~A}$ ) ; une vingtaine de $\mu$ en arrière du salivarium, la cavité pharyngienne prend une forme en T. A ce niveau, le toit du pharynx s'épaissit, principalement dans le plan médian où il donne naissance à une tige pleine, fortement sclérifiée ; cette tige a des parois latérales concaves et la paroi ventrale porte trois arêtes, deux latérales et une médiane (fig. 14 B; photo 18). En arrière, sur une longueur de $15 \mu$, la tige est bordée latéralement par deux cavités qui fusionnent ensuite dorsalement pour former la chambre postérieure («posterior part of closed chamber » de Bertram); la tige se trouve donc ainsi suspendue à une très mince lame 
parallèle au toit du pharynx (fig. $14 \mathrm{C}$; photo 18). Les angles des parois latérales du pharynx, très souples dans cette région, portent chacun un sillon qui fait face aux arêtes latérales de la tige; à ce niveau, la tige saillante et les parois du pharynx donnent l'impression de pouvoir s'engrener exactement (photo 18).

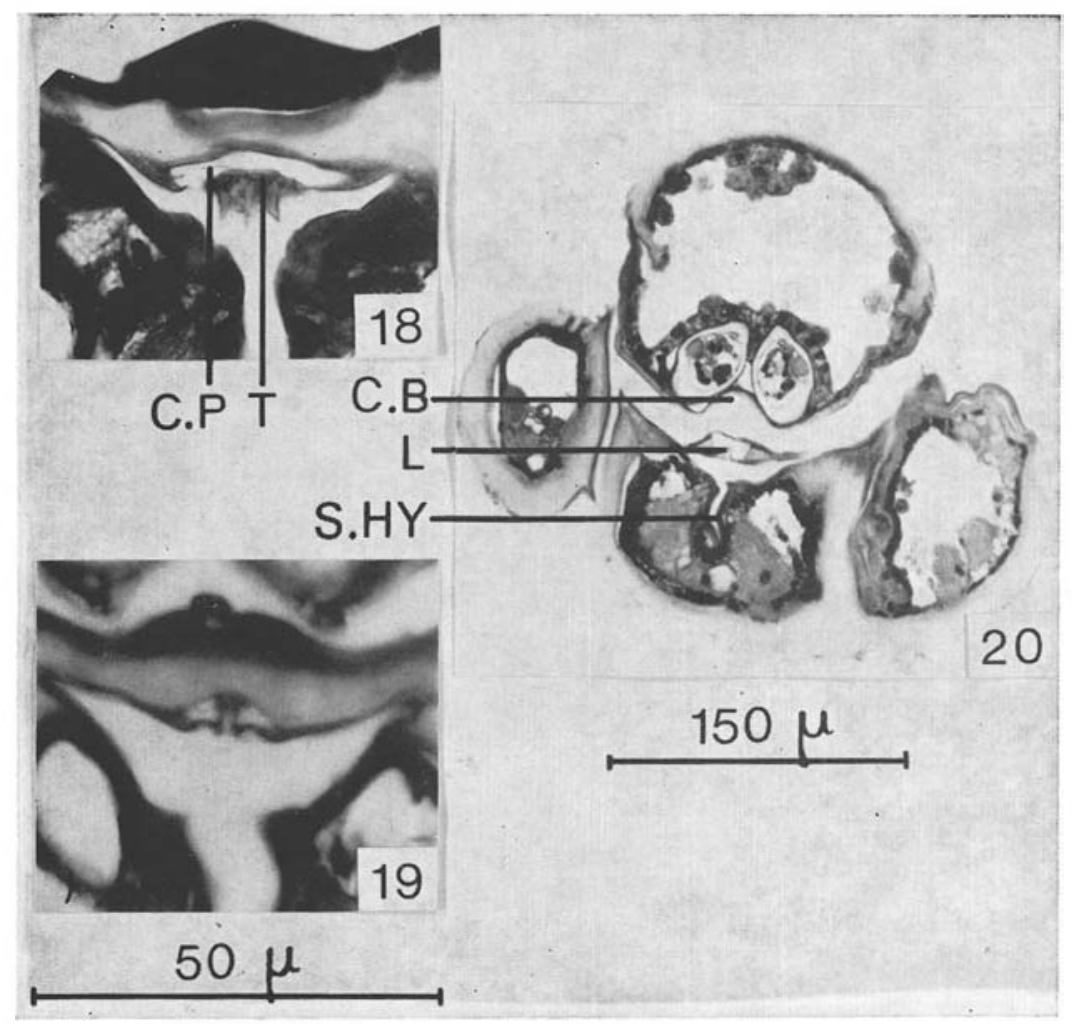

Photos 18 et 19. - Détails du toit du pharynx. 18: La tige est suspendue à la paroi ventrale souple de la C.P. et peut s'engrener dans les angles du pharynx. 19: Coupe juste en arrière de l'orifice pharyngien (échelle : $50 \mu$ )

Рното 20. - Coupe transversale du rostre, au niveau de la cavité buccale (échelle : $150 \mu$ )

L'orifice pharyngien est situé à $45 \mu$ en avant du fond du salivarium; le toit du pharynx, détaché des parois latérales, constitue le labre, long de $130 \mu$ (fig. $14 \mathrm{E}$; photo 20). Celui-ci se présente comme une languette effilée qui recouvre d'abord le sillon hypostomien ventral, puis la gouttière hypostomienne. Le labre est creux dans sa première moitié ; une chambre labrale continue en effet la chambre postérieure du toit du pharynx; sa paroi est mince et souple, mais elle est doublée dans les angles par des coins fortement sclérifiés; la tige qui était appendue à la chambre Annales de Parasitologie humaine et comparée (Paris), t. 42, 1967, $\mathrm{n}^{\circ} 2$ 
postérieure se continue dans la chambre labrale, mais devient interne (fig. $14 \mathrm{E}$ et $\mathrm{F}$; photo 19); coins et tige médiane fusionnent dans la partie distale pleine du labre.

La musculature pharyngienne varie aussi de l'arrière vers l'avant; à la base du rostre, il y a les muscles constricteurs et dilatateurs décrits précédemment (fig. $14 \mathrm{~A}$ ), puis, quand la cavité pharyngienne prend sa forme en T, il n'y a plus que quelques muscles dilatateurs (fig. $14 \mathrm{~B}$ ); les petits muscles dorsaux qui exercent une traction sur le toit du pharynx finissent par disparaître (fig. $14 \mathrm{C}$ ) ; la paire de muscles latéroventraux qui s'appuie sur le sillon hypostomien ne persiste pas au niveau de la gouttière hypostomienne (fig. $14 \mathrm{~F}$ ).

Le déroulement du repas chez les Ixodoidea paraît être assez constant quelles que soient les espèces étudiées (Arthur, 1946, 1951, 1957; Gregson, 1960). Nous avons pu avoir une indication sur le mode d'alimentation d'O. tartakowskyi en observant des larves hexapodes en train de se gorger sur des souriceaux; la transparence du rostre permet de voir les mouvements du pharynx et le passage du sang. Après la fixation de la Tique sur l'hôte, il y a une période d'inaction qui est plus ou moins longue (de quelques minutes à une demi-heure); elle est parfois interrompue par quelques brèves aspirations de sang.

Après cette phase de mise en action, durant laquelle une grande quantité de saiive doit être excrétée pour lyser le derme et les capillaires, les alternances d'activité et de repos s'accélèrent pour devenir très rapides ; chez une larve déjà à demi gorgée et fixée sur l'hôte depuis 20 à $25^{\prime}$, nous avons pu établir la succession suivante (phase de repos symbolisée par - ; phase active par +): $-17^{\prime \prime},+63^{\prime \prime},-5^{\prime \prime},+33^{\prime \prime}$, $-2 ",+6 ",-5 ",+55^{\prime \prime},-3^{\prime \prime} \ldots$ Durant chaque période active, les mouvements du pharynx sont si rapides que les gorgées se fondent le unes dan les autres pour former un flux continu de sang; après chaque série de 6 ou 8 palpitations du pharynx, il y a une contraction plus forte qui se traduit par l'aspect très blanc du rostre.

L'aspiration du sang est provoquée par la dépression qui règne dans le pharynx lorsque celui-ci se dilate; du même coup le sang des caeca tend à être régurgité. Pour empêcher ce phénomène, $O$. tartakowskyi possède un mécanisme de sécurité assez original, bien que non dépourvu d'analogie avec celui d'O. moubata. La coaptation précise entre la tige pharyngienne et les angles du pharynx paraît indiquer que ce système d'occlusion fonctionne surtout au niveau et en arrière de l'orifice pharyngien. Selon l'hypothèse de Bertram, l'appareil cavitaire oral renferme de l'hémolymphe, qui va et vient selon l'état de contraction du pharynx; bien que nous n'ayions pas mis en évidence de coagulum dans les cavités d'O. tartakowskyi, nous utiliserons cette hypothèse.

La contraction de tous les muscles du pharynx ne doit pas se faire simultanément, mais se propager d'avant en arrière; nous allons donc imaginer ce qui se passe en un point précis du pharynx, par exemple au niveau de la figure $14 \mathrm{C}$ : une gorgée de sang vient d'être ingurgitée; les deux muscles constricteurs sont relâchés; les parois du pharynx remontent et s'appliquent étroitement à la tige saillante. Pour absorber une nouvelle gorgée de sang, les muscles dilatateurs de la partie antérieure entrent en activité ; la dépression provoquée entraîne à la fois un appel de sang de 

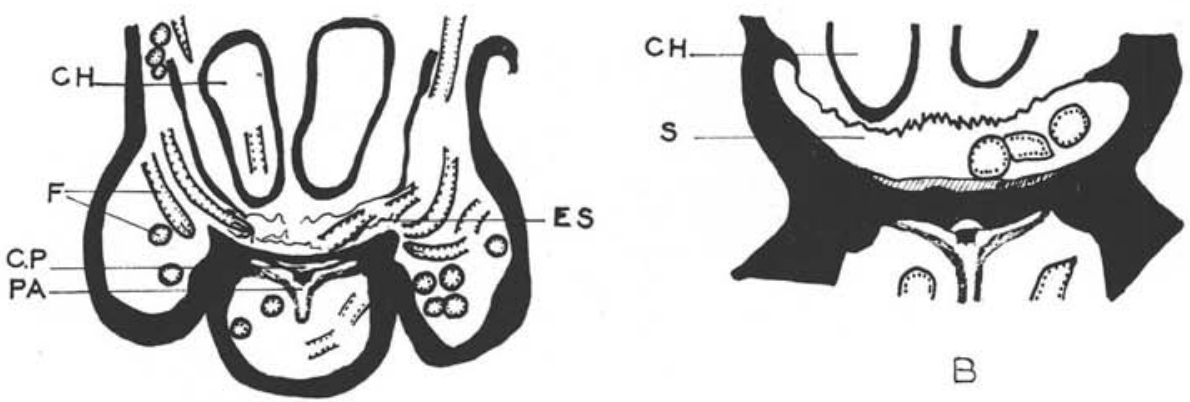

A
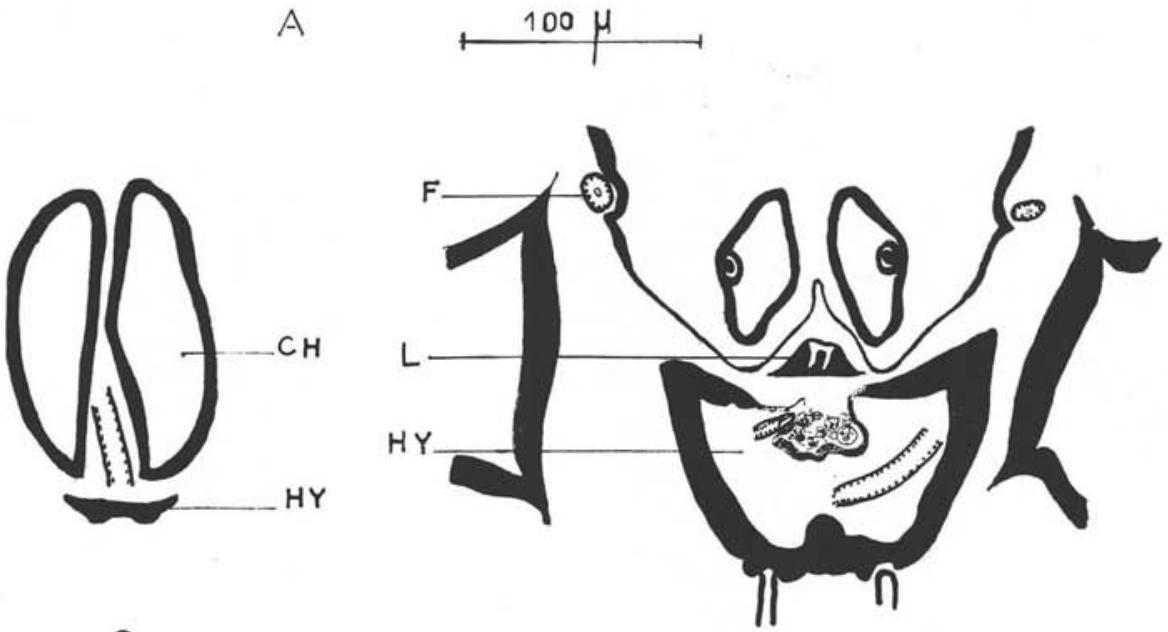

C
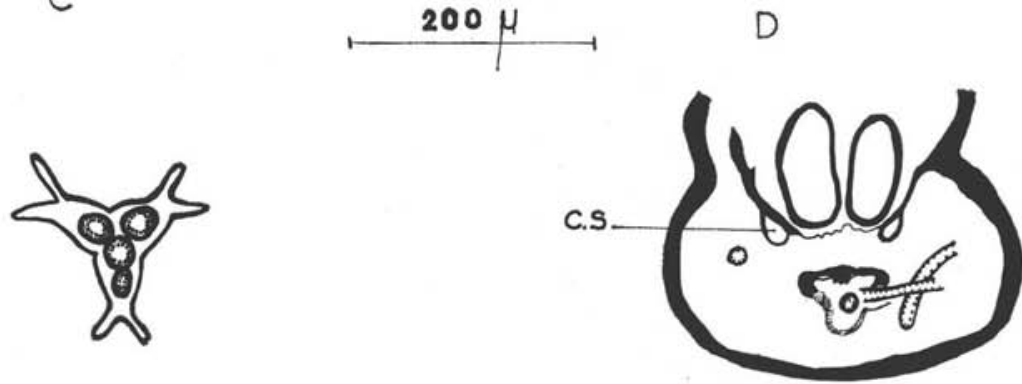

$E$

F

Fig. 16. - Ornithodores piquant depuis cinq minutes : A) effraction du pharynx; B) plus antérieurement, filaires emprisonnées dans le pharynx; C) filaires dans le canal buccal délimité par les chélicères et la languette hypostomienne; D) deux filaires ont glissé très latéralement à l'extérieur du salivarium ; une filaire crève la gouttière hypostomienne; E) filaires dans le pharynx; F) effraction du pharynx 
l'hôte et une arrivée d'hémolymphe dans le labre ; turgescent, il doit s'appliquer sur la gouttière hypostomienne et obstruer le salivarium. Le sang qui arrive presse le labre et repousse l'hémolymphe vers la chambre postérieure; elle est donc très gonflée au moment où les muscles, à ce niveau, commencent à exercer une traction sur le pharynx; la tige saillante, repoussée par l'hémolymphe, agrippe les parois du pharynx et réalise un bouchon empêchant le sang des caeca de refluer vers la zone de dépression; quand la traction musculaire est trop forte, le système d'attache saute brutalement et le sang peut passer, mais déjà, en avant, les muscles sont relâchés et la gouttière hypostomienne fermée.

Il est possible aussi que le labre ait un mouvement de bascule: les muscles obliques dorsaux, visibles sur la figure $14 \mathrm{~B}$, en se contractant, soulèvent normalement le pharynx, mais en $C$, il est fixé aux pédipalpes; ceux-ci forment un axe autour duquel basculerait le toit du pharynx et son prolongement, le labre; quand le toit se soulève, le labre s'abaisserait sur l'hypostome et améliorerait la fermeture du sillon.

Nous allons nous appuyer sur ces hypothèses pour tenter d'expliquer les particularités constatées, dans la transmission des larves.

Passage des filaires a travers le cône buccal

Sur les 25 spécimens infestés, prélevés en cours de repas, seulement quatre montrent des larves (1 à 3) en train de s'échapper, ces spécimens s'étant gorgés sur Cobaye ou sur Hamster.

Les larves empruntent deux voies différentes:

1) Le salivarium. Nous avons déjà signalé la grande abondance des filaires entre le plateau sous-chélicérien et le toit du pharynx. C'est précisément dans cette région que se forme le salivarium, dont les parois cuticulaires sont particulièrement minces. Les filaires rompent cette paroi et s'infiltrent dans le salivarium. Elles glissent dans le canal buccal limité dorsalement par les chélicères et ventralement par le labre (fig. 16 A et $\mathrm{B}$; photo 21 ).

2) Le pharynx. Bon nombre de filaires sont aussi massées entre les muscles pharyngiens ventraux. Les parois latérales dans la moitié antérieure du pharynx sont assez minces et peuvent être rompues par les filaires (fig. $16 \mathrm{D}$ et $\mathrm{F}$; photo 22 et 23). Celles-ci vont vers l'orifice buccal et continuent leur progression dans la gouttière hypostomienne (fig. $16 \mathrm{C}$ et $\mathrm{E}$ ).

Les filaires libérées par effraction, soit du salivarium, soit du pharynx, sont très vraisemblablement inoculées directement dans le derme : dans trois cas, en effet, les filaires ont pu être suivies sur coupes bien au-delà des deux soies qui sont tangentes à la peau lors du repas (1); dans le dernier cas, la filaire n'a fait que rompre le pharynx et n'est pas encore passée dans le canal alimentaire.

(1) Lors de la piqûre, l'Ornithodore enfonce dans la peau de l'hôte ies chélicères et l'hypostome ; celui-ci est enfoui presque jusqu'au niveau où les pédipalpes se soudent au rostre, niveau facilement reconnaissable grâce à la présence de deux grosses soies portées par la paroi ventrale de l'hypostome (fig. $14 \mathrm{~F}$ ), situé à $190 \mu$ de l'apex. La pointe de la languette hypostomienne atteint facilement les capillaires du derme. 
Trois des quatre spécimens sur lesquels on observe le passage des filaires ont été prélevés $5^{\prime}$ après le début de la piqûre; chez six autres prélevés au même moment, aucune filaire ne traverse les pièces buccales; la $4^{\circ}$ Tique positive a été détachée au bout de $12^{\prime}$ environ, mais la quantité de sang contenue dans les caeca est très faible et comparable à celle d'un spécimen de $5^{\prime}$. Les autres Tiques prélevées à $30^{\prime \prime}, 1^{\prime}, 2^{\prime}$,

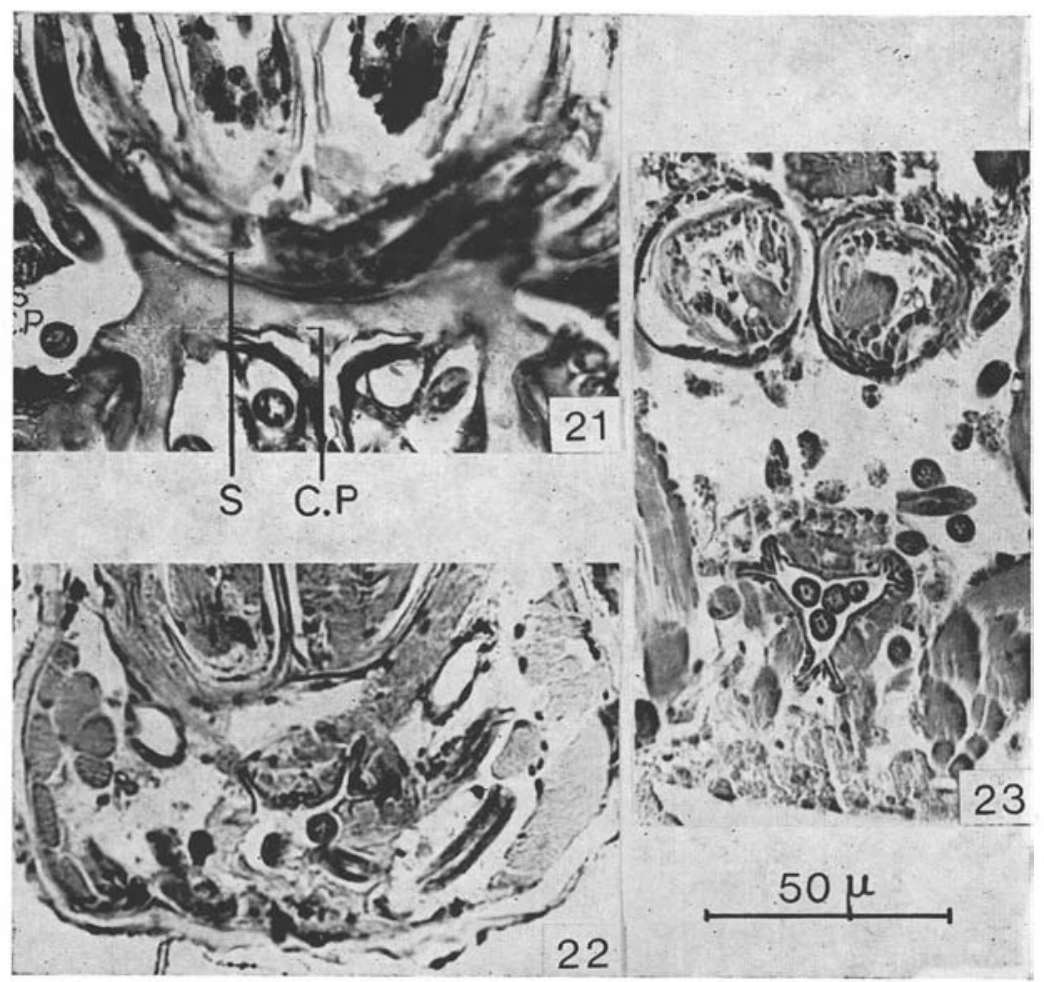

Рното 21. - Filaires dans la salivarium déchiré (5' de piqûre)

Рното 22. - Effraction du pharynx par une filaire (15' de piqûre)

Рното 23. - Filaires dans le pharynx

$7^{\prime}, 15^{\prime}, 45^{\prime}$ et 1 h 30 sont négatives pour la transmission. Deux constatations sont à tirer de ces faits :

1) L'extrême rareté du passage des filaires: il peut traduire le fait que réellement un très petit nombre de filaires sont inoculées à chaque repas, et pas par chaque Tique (après un repas, la Tique contenant des larves infestantes en renferme un bon nombre), ou il peut être une conséquence du procédé de prélèvement. Dans cette seconde hypothèse, le pharynx et le salivarium devraient présenter très souvent des traces d'effraction; or, une seule Tique, prélevée à la $15^{\circ}$ minute, montre une déchirure du pharynx. 
2) Les filaires semblent passer surtout au début du repas, pendant la phase lente de mise en action du pharynx: les quatre Tiques positives pour la transmission n'ont pas encore prélevé de sang, ou en quantité minime, comme en témoigne la rareté des globules blancs dans les caeca.

Quand débute le véritable repas, l'activité des muscles dilatateurs et constricteurs du pharynx permet alternativement d'aspirer et de refouler les gorgées de sang. Durant cette période, on peut supposer que les filaires ne peuvent généralement pas sortir: le courant sanguin, alterné avec la constriction du pharynx, refoule les filaires, et la turgescence rythmique du labre obstrue le salivarium et l'orifice pharyngien. L'hypothèse de filaires repoussées vers l'arrière avec l'afflux de sang semble être appuyée par la présence, assez rare il est vrai, de filaires dans les caeca, alors que les parois de ceux-ci semblent ne présenter aucune rupture.

En conclusion, la piqûre de l'Ornithodore sur le Hamster provoque une migration rapide et intense des filaires vers la région buccale; elles vont le plus antérieurement possible et se massent essentiellement dans le cône buccal. Les causes de cette migration nous échappent et il faudrait des études expérimentales pour les élucider; la chaleur qui doit régner dans la portion du rostre qui est dans la peau peut être un des facteurs déterminants de ce mouvement; on peut aussi invoquer une attraction chimique, dont l'effet serait plus ou moins intense suivant l'espèce de Rongeur adoptée (1).

Les filaires sortent par deux voies différentes: le salivarium et le pharynx; dans les deux cas, elles doivent rompre des parois chitineuses, mais minces. Cette rupture se fait en des points quelconques, au hasard des contorsions des larves (2).

Le nombre de filaires transmises à chaque repas paraît très faible. La transmission peut être gênée par la résistance finalement assez grande des parois chitineuses des conduits salivaire et pharyngien, et aussi par le mécanisme alimentaire lui-même puisque, alternativement, le sang qui afflue, ou le labre turgescent, opposent un barrage au passage des filaires. Celles-ci ne trouveraient donc une issue que pendant la période de salivation pré-alimentaire. Un fait est sûr: l'absorption de sang ne conditionne pas la sortie des filaires puisque, chez une Tique à musculature pharyngienne détruite, et donc incapable de se nourrir, une filaire traversait le salivarium et était en cours d'inoculation.

Si le nombre des filaires qui quittent l'Ornithodore est réduit (3), les chances de développement chez l'hôte définitif doivent être grandes puisqu'elles sont inoculées jusque dans le derme.

(1) La Tique observée par Chabaud avec six larves infestantes sortant du rostre avait piqué un Mérion, Meriones libycus; supposant une influence de l'hôte, nous avons gorgé certaines Tiques infestées sur des Mérions, mais nous n'avons pas eu plus de succès qu'avec celles qui s'étaient gorgées sur Hamster ou sur Cobaye.

(2) Les mouvements des larves pourraient être accélérés dans le rostre qui, comme nous l'indiquons précédemment, doit avoir une température plus élevée. Chez des Tiques laissées dans une étuve à $37^{\circ}$, les mouvements des filaires sont plus rapides.

(3) Depuis la rédaction de ce travail, des expériences, qui permettent de compter le nombre de filaires inoculées au cours d'un repas, ont été effectuées. Elles montrent que ce nombre est plus grand (environ une quinzaine) que nous ne le pensions. 


\section{CHAPITRE VI}

\section{L'évolution chez ORNITHODOROS ERRATICUS}

Selon Chabaud (1954), Ornithodoros erraticus (Lucas 1849) n'est pas un hôte favorable au développement de Dipetalonema viteae; «l'évolution est bloquée dès le début du deuxième stade larvaire . Nous avons cherché à mettre en évidence les divers modes de réaction de cette Tique vis-à-vis de la filaire.

$O$. erraticus semble s'infester aussi bien qu'Ornithodoros tartakowskyi en se gorgeant sur un Hamster bien positif.

Pour un certain pourcentage de microfilaires, la première étape du développement est identique chez les deux espèces de Tiques: traversée de la paroi digestive et passage dans la cavité générale ; ensuite plusieurs larves pénètrent dès les premières heures dans les muscles, quel que soit le type et la localisation de ceux-ci; d'abord mobiles, elles s'immobilisent au bout de quelques jours.

Mais une très forte proportion de microfilaires est incapable d'atteindre le stade de la pénétration dans les muscles. Elles restent libres dans la cavité générale ou ne traversent même pas les caeca digestifs.

A cause du pourcentage particulièrement élevé des filaires bloquées dans l'appareil digestif, il est aisé de suivre chez $O$. erraticus les mécanismes de destruction des microfilaires dans les caeca. Cette destruction est assez lente et ces divers aspects s'observent simultanément sur des Ornithodores fixés au $13^{\circ}$ jour. Dans les caeca les filaires ne s'accroissent pas et leur colorabilité s'affaiblit; leurs noyaux sont souvent plus espacés et disposés très irrégulièrement; de telles filaires, en partie lysées, restent cependant un peu mobiles; certaines d'entre elles sont plus ou moins recouvertes de granules mélaniques; parfois ce sont des microfilaires à colorabilité normale sur lesquelles la mélanine se dépose.

Les cellules digestives qui, au $13^{\circ}$ jour, font saillie dans la cavité digestive et peuvent même rompre leurs attaches avec l'épithélium, renferment parfois des fragments de filaires en voie de digestion, ou bien à des degrés divers de mélanisation. Ces cellules renferment aussi de nombreux granules noirs provenant de la digestion du sang' et des globules blancs qu'elles ont phagocytés (fig. $17 \mathrm{~A}$ ); elles semblent jouer un rôle dans l'élimination des déchets de la digestion.

Dans la cavité générale, les filaires ne s'accroissent pas davantage. Les microfilaires offrent les mêmes aspects que dans les caeca: larves digérées peu colorables, larves mélanisées, soit avec dépôt externe de mélanine, soit avec mélanisation localisée au niveau des noyaux. Elles sont généralement parfaitement libres ; mais parfois elles voisinent avec quelques haemocytes granuleux. Ceux-ci paraissent assez inactifs ; mais, au début de l'infestation, ils peuvent phagocyter des microfilaires (fig. 17 B) ; ce phénomène a été très rarement observé. Il ne se forme jamais de capsules autour des parasites. 
Parmi les filaires qui ont réussi à pénétrer dans une fibre musculaire, une petite quantité ne s'accroît pas et est détruite avec ou sans mélanisation (fig. $17 \mathrm{C}$, photo 24). Mais, la plupart d'entre elles commencent à se développer ; au $13^{\mathrm{e}}$ jour, elles peuvent avoir une taille comparable à celles qui parasitent $O$. tartakowskyi. Mais leurs noyaux sont souvent peu colorables et des grains de mélanine plus ou moins abondants recouvrent leur cuticule.

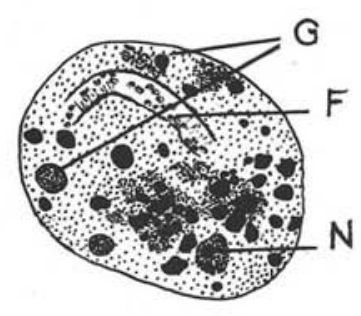

A

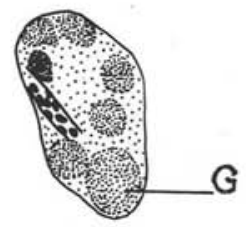

B

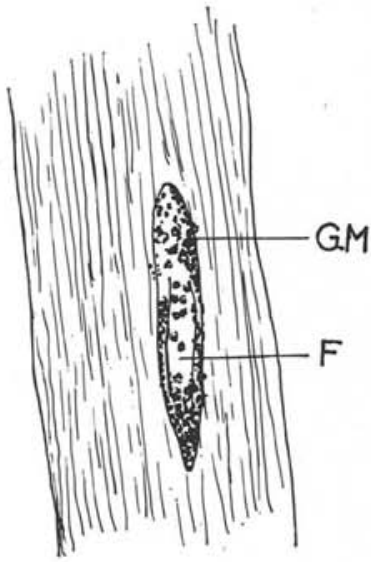

C

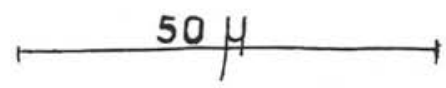

FIG. 17. - Ornithodoros erraticus (13 jours après le repas infestant): A) microfilaire détruite et légèrement mélanisée dans une cellule digestive séparée de l'épithélium; B) microfilaire dans un haemocyte; C) forte mélanisation d'une microfilaire dans un muscle

La suite du développement varie d'une façon importante avec les souches d'O. erraticus infestées. Chez la petite variété originaire de Taghjicht, plusieurs filaires atteignent le troisième stade et se libèrent, mais le pourcentage de réussite des parasites reste bien inférieur à ce qu'il était chez $O$. tartakowskyi. Chez la grande variété originaire du Maroc (O. erraticus erraticus), presque toutes les filaires sont détruites et, vers le $20^{\circ}$ jour, les Ornithodores paraissent totalement négatifs. Chez quelques rares spécimens, deux ou trois filaires continuent toutefois à se développer dans les muscles et atteignent une taille normale. Une fois même, une de ces larves, presque mûre, a été observée dans les cellules d'un tube de Malpighi.

L'infestation d'O. erraticus par D. viteae permet donc de mettre en évidence chez cette espèce diverses étapes de défense : barrage digestif, barrage au niveau de la cavité générale et enfin barrage au niveau des muscles.

Le premier système de défense existe déjà chez $O$. tartakowskyi, mais ici, d'une part il est plus efficace, d'autre part, il fait intervenir en plus d'une destruction extracellulaire une véritable phagocytose par les cellules de l'épithélium digestif. 
Au niveau de la cavité générale, il ne se forme jamais de capsule, mais les haemocytes sont parfois capables de phagocyter les microfilaires; la majorité meurt sans qu'on puisse mettre en évidence un processus cellulaire de défense, soit par inanition et autolyse, soit par action chimique de l'haemocoele sur les microfilaires.

Pното 24. - Fibre musculaire lisse d'Ornithodoros erraticus contenant une microfilaire mélanisée; les bords de la vacuole sont recouverts de granules de pigment (fixation 13 jours après le repas infestant)

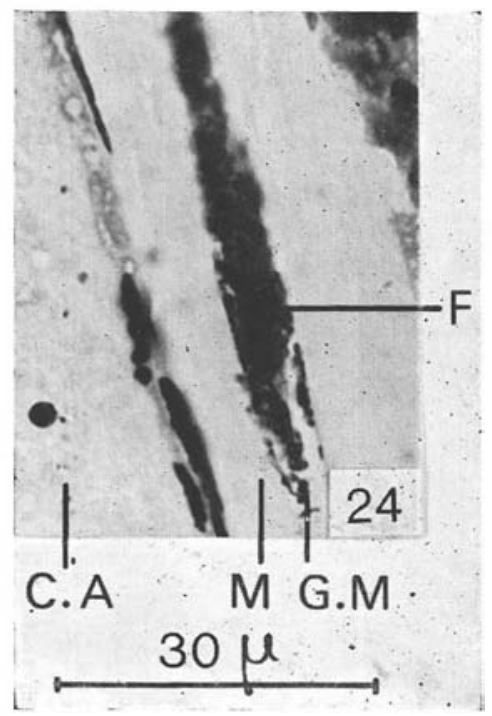

Les muscles eux-mêmes sont capables de réactions de défense par lyse et mélanisation des parasites. Cette destruction est plus ou moins rapide et le degré de développement que peuvent atteindre les larves varie énormément d'une souche d'O. erraticus à une autre et, à l'intérieur de la souche, d'un spécimen à l'autre ; au sein même de l'hôte, les possibilités d'évolution des larves varient à l'extrême: alors que la majorité des filaires est détruite dans les fibres musculaires, soit au début du deuxième stade, soit avant le début de la croissance, quelques très rares parasites peuvent se développer normalement.

La tolérance des hôtes intermédiaires vis-à-vis de Dipetalonema viteae varie donc beaucoup entre deux espèces voisines et même d'une souche à l'autre. Mais cette très étroite spécificité du parasite s'oppose à la faculté qu'il a de se développer dans divers organes: les fibres musculaires principalement, mais aussi les tubes de Malpighi chez $O$. erraticus, et les acini venimeux chez $O$. tartakowskyi. La réussite dans le développement de la filaire ne semble pas tellement dépendre de la forme sous laquelle sont fournis les aliments, mais plus vraisemblablement de la qualité des unités chimiques qui les constituent: ainsi la myosine peut être remplacée par les protides cytoplasmiques des acini venimeux.

Le développement très inégal des filaires à l'intérieur d'un même hôte intermédiaire, alors qu'elles vivent dans les fibres musculaires ayant la même composition 
chimique globale, fait supposer l'existence d'une ou de quelques substances indispensables au développement du parasite et dont la répartition est inégale chez le vecteur. Ces substances pourraient s'apparenter au groupe des oligo-éléments et des vitamines et constituer peut-être un co-enzyme indispensable à l'action des enzymes filariens sur la cellule-hôte.

\section{Conclusion}

Le développement larvaire de Dipetalonema viteae (Onchocercidae) est, dans ses grandes lignes, comparable à celui des autres espèces de cette famille (ingestion des microfilaires par un vecteur haematophage, développement jusqu'au troisième stade infestant, transmission à l'hôte définitif au moment de la piqûre); mais il présente quelques particularités, dont certaines ont une signification évolutive, telles que la durée de la maturation, le mode de croissance pendant le premier stade larvaire, et le type des organes parasités.

\section{DuréE DE LA MATURATION}

Chabaud (1954) a montré tout l'intérêt qui résidait dans l'étude de ce caractère biologique: à une espèce morphologiquement évoluée à l'état adulte correspond un développement larvaire accéléré.

A $27^{\circ}$, chez Ornithodoros tartakowskyi, il faut 25 à 27 jours pour que les microfilaires se transforment en larves infestantes.

Cette durée paraît longue si on la compare à celle de nombreuses autres filaires (Chabaud, 1954) ; les temps de maturation les plus courants varient entre 9 et 12 jours (Noë, 1901 ; Bernard et Bauche, 1913 ; Connal et Connal, 1922 ; Causey, 1939 ; Hopkins et Nicholas, 1952; Nelson, 1962), et peuvent se réduire à 6 jours, comme c'est le cas pour Wuchereria malayi (Brug, 1931 ; Feng, 1936).

Dipetalonema viteae, par la lenteur de son développement, se rapproche de quelques espèces parasites de Reptiles: Macdonaldius oschei, chez Ornithodoros talaje, atteint sa maturité en 25 jours (Frank, 1964); Oswaldofilaria chlamydosauri atteint sa maturité en 30 jours chez un Culicide (Mackerras, 1953).

\section{MODE DE DÉVELOPPEMENT PENDANT LE PREMIER STADE}

Dans la famille des Onchocercidae, l'évolution des larves chez l'hôte intermédiaire débute généralement par un raccourcissement et surtout un épaississement du corps ; il est convenu d'appeler ce nouvel aspect «stade en saucisse 》 (Noë, 1901, 1908 ; Feng, 1936; Desportes, 1942 ; Schacher, 1962). Il s'observe aussi dans des familles voisines : Shoho et Nair (1960) le décrivent chez un Setariidae Setaria digitata ; il existe même chez quelques Spirurides, parmi les espèces morphologiquement les plus évoluées, comme les Habronèmes (Roubaud et Decazeaux, 1921). 
Le «stade en saucisse » ne correspond pas uniquement à un changement externe ; durant cette période, l'anatomie interne s'organise rapidement; ainsi, deux jours et demi après son ingestion par l'Anophèle vecteur, Wuchereria malayi présente déjà un tube digestif différencié (Feng, 1936).

Dipetalonema viteae, au contraire, ne présente pas de «stade en saucisse » et son organisation est lente : le $10^{\circ}$ jour, son tube digestif n'est pas encore individualisé (Chabaud, 1954).

D'autres Dipetalonema présentent les mêmes particularités : ce sont Dipetalonema mansonbahri, dont le vecteur est une Puce et qui se développe dans le tissu adipeux en 15 à 18 jours (Nelson, 1961) ; Dipetalonema grassii, dont le vecteur est une Tique, Rhipicephalus, et qui se développe dans la cavité générale, en un temps non connu (Noë, 1908). Un autre genre, Macdonaldius oschei, déjà cité pour la lenteur de son développement, ne présente pas non plus de «stade en saucisse ».

L'existence de ce stade est en effet généralement liée à un développement larvaire accéléré s'effectuant le plus souvent chez des vecteurs à métabolisme élevé, par exemple des Diptères; de telles larves ont en général une forte «séclusion » et sont des parasites intra-cellulaires ; exceptionnellement ils se développent dans la cavité générale (Litomosoides carinii, selon Williams, 1948). Le «stade en saucisse » peut s'interpréter comme une adaptation à la vie intracellulaire de la larve et il ne s'observe pas chez des espèces morphologiquement primitives.

Il est remarquable en effet de constater que, parmi les trois espèces de Dipetalonema dépourvues de «stade en saucisse » deux ont été classées par Chabaud (1952) dans les formes à morphologie primitive; Dipetalonema mansonbahri Nelson 1961 présente aussi des caractères peu évolués. Ces trois espèces parasitent soit des Carnivores, soit des Rongeurs, et leurs vecteurs sont des Tiques ou des Puces.

Elles s'opposent aux Dipetalonema parasites de Primates, qui présentent à la fois une morphologie évoluée, un «stade en saucisse» et une durée de maturation courte dans les muscles alaires de Diptères vulnérants: neuf jours pour $D$. perstans selon Hopkins et Nicholas (1952) et huit jours pour D. streptocerca selon Chardome et Peel (1951).

\section{Types de CELlules ParasitéEs}

En règle générale, les filaires, si elles ne se développent pas dans l'haemocoele, infestent un type précis et unique d'organes: soit les tubes de Malpighi (Noë, 1901 ; Weber et Hawking, 1955 ; Pistey, 1956), soit le tissu adipeux (Connal et Connal, 1922 ; Highby, 1943 ; Weber, 1955 ; Nelson, 1961, 1963), soit les muscles (Blacklock, 1926 ; Abe, 1937 ; Buckley, 1938 ; Desportes, 1942 ; Nelson, 1962).

Or, Dipetalonema viteae peut parasiter divers types de cellules et s'y développer ; ce sont les fibres musculaires, les acini venimeux et les tubes de Malpighi (un seul cas, chez $O$. erraticus). Ces trois types de cellules ont en commun l'existence dans leur cytoplasme de glycogène. La présence de cette substance n'est pas suffisante pour expliquer la sélection de ces trois types de cellules: les vésicules séminales sont en 
effet très riches en glycogène, mais nous n'avons jamais observé de filaires dans ces organes; dans ce cas, il est vrai, la paroi épaisse qui les entoure peut être un obstacle mécanique à la pénétration des microfilaires.

Les larves, chez Ornithodoros tartakowskyi, peuvent se développer aussi bien dans les muscles striés que dans les muscles lisses et ont une répartition quelconque dans le corps du vecteur. Ceci peut s'expliquer par l'anatomie particulière de l'appareil digestif : les caeca digestifs ramifiés emplissent tout le corps et la structure de leurs parois est uniforme: épithélium simple non doublé d'une membrane péritrophique interne; les microfilaires peuvent traverser les parois digestives en des points quelconques. Il doit en être de même pour les autres filaires se développant aussi chez des Acariens (Litomosoides carinii, Macdonaldius oschei).

$\mathrm{Au}$ contraire, dans le cas le plus général où le vecteur est un Insecte haematophage, il semble qu'il y ait des lieux précis d'effraction, soit au niveau du cardia (Lebied, 1961), soit à l'extrémité postérieure du mésentéron (Wharton, 1957). Dans ce dernier cas, si les filaires parasitent les muscles alaires, elles doivent effectuer une migration vers le thorax, qui laisse supposer l'existence de tropismes vis-à-vis d'organes précis, phénomène qui n'apparaît pas chez Dipetalonema viteae.

Tous ces caractères biologiques, d'une part maturation larvaire lente et absence de «stade en saucisse » tous deux signalés par Chabaud en 1954, d'autre part variabilité des lieux de développement, font de Dipetalonema viteae une filaire relativement primitive, et nous avons vu les ressemblances qu'elle avait avec certaines filaires de Reptiles, et particulièrement avec Macdonaldius oschei qui se développe aussi chez une Tique.

Certains éléments du développement larvaire, joints à d'autres caractères non encore rapportés, nous ont fait approcher deux problèmes: le premier concerne les particularités de la transmission du parasite à l'hôte définitif ; le deuxième les relations entre la larve parasite et l'hôte vecteur.

\section{Particularités de la transmission chez Dipetalonema viteae.}

Les variations dans le mode de transmission des parasites chez les Onchocercidae semblent correspondre à des différences dans le comportement des vecteurs lors de leurs repas de sang: chez les Diptères haematophages, par exemple, les troisièmes stades infestants emplissent le labelle et sont déposés lors de la piqûre sur la peau de l'hôte dans laquelle ils pénètrent activement (Noë, 1901; Gibbins, 1938 ; Gaillard, 1941; Gordon et Crewe, 1953); chez les Acariens, l'ensemble des pièces buccales pénètre dans la peau (Bertram, 1939; Arthur, 1946, 1951, 1957 ; Gregson, 1960) et les larves sont très probablement inoculées. Nous avons pu suivre, en effet, chez Ornithodoros tartakowskyi les stades infestants jusqu'à la pointe du rostre.

La transmission chez ce vecteur se présente sous un aspect particulier: les troisièmes stades sont répartis dans le corps de l'Ornithodore, mais il y a de plus fortes concentrations là où les organes laissent des espaces libres (ex. : vide sus-chélicérien). L'acte de piquer détermine une migration rapide des filaires vers le rostre; les causes précises de ce mouvement restent inconnues. 
Frank (1964) observe un phénomène différent chez un vecteur très voisin, $O$. talaje, avec Macdonaldius oschei; les larves vivent dans les tubes de Malpighi; à maturité elles s'échappent et se dirigent vers les pièces buccales, s'enfonçant entre les faisceaux musculaires, avant que le vecteur n'ait piqué.

Les observations de Frank sont conformes aux conclusions les plus courantes des auteurs sur les diverses espèces de filaires; les migrations spontanées des troisièmes stades vers les pièces buccales, indépendantes du comportement alimentaire des vecteurs, ont été signalées par Noë (1901), Blacklock (1926), Steward (1937), Gaillard (1941), Wharton (1957), Nelson (1963), et beaucoup d'autres. Il ne s'agit pas là d'une règle absolue: les larves de Loa loa sont uniformément réparties dans le corps de Chrysops silacea (Lavoipierre, 1958) leur migration est provoquée par le repas et est très rapide (Gordon et Crewe, 1953) ; les larves infestantes de Foleyella furcata ne se rassemblent pas dans la tête du moustique vecteur (Brygoo, 1966, communication orale) ; chez l'Acarien Bdellonyssus bacoti, les troisièmes stades de Litomosö̈des carinii se répandent dans tout le corps (Williams, 1948).

On conçoit aisément une migration conditionnée par le repas, mais beaucoup plus mal une migration spontanée. On peut se demander si le tropisme spontané des larves mûres vers les pièces buccales ne pourrait pas être parfois une conséquence des conditions d'élevage des vecteurs; dans de nombreux cas, en effet, en dehors des repas de sang, on donne aux vecteurs la possibilité de se gorger à volonté sur des surfaces humides, parfois sucrées (par exemple Le Corroler, 1957) ; or Noë (1901) a montré que $D$. immitis pouvait être déposé par Anopheles claviger dans du jus de raisin, et on peut supposer que les larves, attirées alors vers les pièces buccales, y restent concentrées.

En fait, le phénomène de la migration des larves est sans doute complexe comme le montre l'expérience de Newton et Pratt (1945): ils inoculent des larves du troisième stade de Wuchereria bancrofti à des moustiques sains et les retrouvent, peu de temps après, dans la tête et le labium. Les migrations pourraient donc en partie dépendre de certaines propriétés du vecteur (circuiation sanguine entraînant passivement les larves ou d'autres facteurs inconnus).

Rassemblées autour du pharynx et au fond du salivarium, les larves de Dipetalonema viteae s'échappent par effraction du salivarium ou de la moitié antérieure du pharynx, alors que chez Macdonaldius oschei elles passent juste en arrière du pharynx, au niveau de l'œsophage (Frank, 1964).

Ornithodoros tartakowsky, ne perd pas toutes ses larves en un seul repas; il semble même qu'un petit nombre d'entre elles seulement soit inoculé à chaque fois. Le cycle se maintient grâce à des particularités biologiques du vecteur et de la filaire qui compensent la rareté du passage des troisièmes stades : d'une part, l'Ornithodore a la capacité de faire de nombreux repas de sang qui, à chaque fois, peuvent être infestants ; d'autre part, les larves du troisième stade sont nombreuses et ont une très grande longévité (Wattiaux, 1965) ; enfin, elles sont inoculées, ce qui devrait assurer au mieux leur réussite chez l'hôte définitif. 


\section{Relations Vecteur-Parasite : variété des localisations larvaires et étroite spécificité vis-à-vis de l'hôte intermédiaire.}

De nombreux cycles de filaires, et d'autres Nématodes de biologie voisine comme les Spirurides, sont actuellement connus; mais ils ont été généralement étudiés d'un point de vue épidémiologique (recherche du vecteur et mode de transmission), et peu d'auteurs ont porté leur intérêt sur les re!ations entre le parasite et le vecteur à l'échelle histologique; Lavoipierre, en 1958, fait une revue du problème et distingue deux aspects dans les relations hôte-parasite. l'action du parasite sur l'organe parasité, et l'action de défense du vecteur vis-à-vis du parasite.

La larve de Dipetalonema viteae provoque des destructions au niveau des muscles qui l'abritent, ce qui se traduit par une paralysie plus ou moins complète des Ornithodores.

Steward (1932 et 1937) a observé le même phénomène avec Onchocerca cervicalis et $O$. gutturosa qui se développent respectivement dans la musculature d'un Culicoïdes et d'une Simulie; Lebied (1950), sur O. volvulus et Feng (1936), sur Wuchereria malayi, tous deux parasites intramusculaires de Diptères, font les mêmes observations ; les muscles alaires des vecteurs étant partiel!ement détruits, la capacité de vol de ces Insectes est considérablement diminuée. De telles destructions s'observent d'ailleurs régulièrement quel que soit l'organe parasité : Noë (1901) observa le développement de Dirofilaria immitis dans les tubes de Malpighi d'Anopheles claviger: ceux-ci sont peu à peu détruits, transformés en syncytium, puis en vésicules contenant les filaires ; Roubaud et coll. (1936), Bernard et Bauche (1913), et Yen (1938), étudiant le même parasite ou une espèce voisine $D$. repens, confirmèrent ces observations. Le parasite se nourrit donc aux dépens de la cellule-hôte.

Nous avons pu apporter quelques précisions sur le comportement trophique de Dipetalonema viteae en suivant l'évolution du muscle parasité.

Contrairement à ce que pensait Chabaud en 1954, les microfilaires semblent être incapables de se développer dans la cavité générale de l'Ornithodore; elles sont intramusculaires dès le début du premier stade : il suffit que, sitôt sorties du tube digestif, elles rencontrent au hasard de leurs contorsions accélérées (1) une fibre musculaire et y pénètrent.

Durant cette phase du cycle de la larve, les muscles sont totalement passifs et nous ne croyons pas, comme l'écrit Lebied (1961) au sujet de la pénétration d'Onchocerca volvulus dans les muscles de Simulium damnosum, que les fibres musculaires, manifestant une brusque activité au niveau du sarcolemme, «phagocytent » les microfilaires. Lors des dissections faites peu après le repas infestant, nous avons observé toutefois que le sarcolemme se détachait irrégulièrement du myoplasme, formant des anses plus ou moins volumineuses; mais de telles déformations superficielles du muscle s'observent aussi chez des Tiques qui ne sont pas infestées et doivent être interprétées, non comme un phénomène de phagocytose, mais comme un artefact dû aux échanges osmotiques entre la fibre et le milieu artificiel de dissection.

(1) Blacklock, en 1926, travaillant sur Onchocerca volvulus, a remarqué aussi que l'activité des microfilaires augmentait après leur arrivée chez Simulium damnosum. 
Nous ne savons pas par quel processus la filaire traverse le sarcolemme, mais nous pensons qu'il s'agit d'un phénomène chimique: la microfilaire, à l'opposé de nombreuses larves de Spirurides, n'a pas de crochet et des recherches récentes de phosphatases acides effectuées par Petithory (1966) ont montré que la région céphalique possédait une activité enzymatique ; c'est sans doute par ce même procédé chimique que les microfilaires traversent l'épithélium digestif.

La filaire conserve très généralement une position excentrique dans la fibre (ce qui explique que, lors des dissections, elle s'échappe facilement), tout en creusant au cours de sa croissance un tunnel dans le myoplasme. Tout le corps est en contact avec les myofibrilles; mais c'est uniquement en avant de la région antérieure qu'il existe une vacuole en forme de dôme, contenant quelques granules ayant les mêmes affinités tinctoriales que le myoplasme; les fibrilles qui arrivent au niveau de cette vacuole sont peu nettes et fragmentées, tandis que le reste du myoplasme paraît intact et conserve éventuellement sa striation. Les enzymes de la région céphalique de la larve paraissent donc être excrétés et provoquent une digestion externe très locale; les protides du myoplasme sont attaqués, mais nous ne savons pas sous quelle forme ni comment ils sont absorbés, tout au moins au premier stade caractérisé par l'absence de tube digestif. Nelson en 1964, dans une revue générale sur le développement larvaire des filaires, suppose que les produits sont absorbés par toute la surface cuticulaire.

La filaire attaque très progressivement le myoplasme; l'importance des dommages qu'elle provoque dépend du volume de la fibre: une petite fibre est totalement détruite, réduite à un sac sarco'emmique, car sa masse disponible égale ou est inférieure à la masse alimentaire dont la filaire a besoin ; une fibre volumineuse semble au contraire bien supporter le parasitisme, car elle possède un excédent alimentaire très important.

En plus d'une destruction du myoplasme, la fibre parasitée présente des modifications nucléaires; les noyaux qui sont au voisinage du parasite ont souvent un nucléole particulièrement vo'umineux; les noyaux eux-mêmes, chez les fibres parasitées depuis une quinzaine de jours, sont plus gros; la chromatine est répartie normalement en petits massifs. Chez les fibres endommagées, vers le $25^{\circ}$ jour, les noyaux ont un aspect nouveau : ce sont de grosses vésicules, à nucléole très volumineux, simple ou dédoublé, parfois vacuolaire, et à chromatine très rare ; ces noyaux sont hypertrophiés et en voie de dégénérescence; certains d'entre eux sont d'ailleurs partiel'ement détruits par la filaire. Mais il semble qu'avant cette phase finale de lyse, les modifications nucléaires puissent s'interpréter comme une manifestation d'une hyperactivité de la fibre musculaire qui serait induite par le parasite. Les fibres infestées ne paraissent ni plus riches, ni plus pauvres en glycogène que les fibres saines; on peut se demander alors où la filaire a puisé ses réserves en glycogène ; celui-ci pourrait soit être métabolisé par la larve à partir des protides myoplasmiques, soit provenir directement des réserves du muscle; cette dernière hypothèse suppose un apport accru de glycogène dans les fibres infestées puisque cette substance s'y maintient à un taux normal.

Les modifications nucléaires consécutives au parasitisme, bien que rarement décrites, ont déjà été observées par quelques auteurs. Roubaud et Decazeaux (1921), étudiant le développement du Spiruride Habronema megastoma chez la mouche 
domestique, ont montré que les noyaux des tubes de Malpighi infestés étaient hypertrophiés; ils font la même remarque pour $H$. microstomum et $H$. muscae qui vivent dans des cellules adipeuses (1922). Dans un tout autre domaine de parasitologie, on a pu constater que les noyaux des cellu es du foie de Rongeurs infestés par des schizontes exo-érythrocytaires de Plasmodium étaient plus volumineux (Landau et Chabaud, 1965). Il pourrait s'agir ici d'un phénomène assez général, le parasite excitant l'activité nucléaire de synthèse et l'exagéran: à tel point que les noyaux finissent par dégénérer.

Si la larve de Dipetalonema viteae se développe de préférence dans les muscles, striés cu lisses, elle présente la remarquable particularité de pouvoir atteindre sa maturité dans les acini venimeux et très rarement dans les tubes de Malpighi. C'est un phénomène qui n'a jamais été signalé chez les Spirurida, les parasites ayant un lieu de dévelcppement précis et exc'usif: soit l'haemocoele, comme pour Litomosoïdes carinii (Bertram, 1946, 1947 ; Kershaw, 1948 ; Williams, 1948 ; Hugues, 1950 ; Freer, 1953), soit le tissu adipeux comme pour Loa loa (Kleine, 1915; Connal et Connal, 1922), Dirofilaria scapiceps (Highby, 1943) et diverses Dipetalonema (Highby, 1943 ; Nelson, 1961, 1962, 1963), soit dans les muscles comme pour d'autres Dipetalonema (Peel et Chardome, 1951; Hopkins et Nicolas, 1952), pour les Onchocerques et les Wuchereria.

La variabilité des lieux de développement de Dipetalonema viteae pose des problèmes ; le premier concerne la pénétration dans divers types de cellules; celles-ci ont en commun deux caractères: la minceur de leur membrane cytop.asmique et la présence d'une substance glycogénique P.A.S. qui disparaît après action de la salive ; les tubes de Ma!pighi en sont particulièrement riches. Bien que nous n'ayons pas observé de déplacement actif des microfilaires vers les cellules hôtes, il est possible qu'elles présentent un tropisme vis-à-vis de ceriaiens cellules, dû à la présence de substances particulières ; on ne peut incriminer sûrement le glycogène, car dans les vésicu'es séminales, très riches en glycogène, nous n'avons jamais observé de dévelcppement de filaires ; mais dans ce cas, leur membrane épaisse peut être un obstacle mécanique à la pénétration des microfilaires.

Le deuxième problème concerne le trophisme de Dipetalonema viteae; la possibilité de se déve opper dans divers organes qui n'ont pas la même nature cytoplasmique suppose de grandes facultés d'adaptation du complexe enzymatique de la filaire.

Or, contradictoirement, cette filaire ne peut pas se développer chez un grand nombre d'hôtes; ses vecteurs sont uniquement des Ixodidae ou des Argasidae; parmi les hôtes intermédiaires possibles, Chabaud (1954) cite Rhipicephalus sp., et Ornithodoros tartakowskyi ; on peut y ajouter O. moubata (Terry, Terry et Worms, 1961) ; O. erraticus, selon les souches, est totalement réfractaire ou permet un développement partiel, avec un faible rendement.

Chez cette espèce en effet, les réactions de l'hôte sont importantes. Il n'y a jamais d'encapsulement par prolifération des cellules sanguines ; mais les larves sont détruites au stade microfilarien, au cours de la croissance, de diverses façons.

- La mélanisation du parasite (ou «chitinisation», selon d'autres auteurs tel 
Brug 1932), qui peut s'observer dans le tube digestif, aussi bien que dans la cavité générale ou les muscles, est le mode le plus courant de destruction. Divers auteurs l'ont observé chez d'autres nématodes: Frank (1964) sur Macdonaldius oschei, parasite à l'état larvaire d'O. talaje; Feng (1936) sur Wuchereria malayi; Highby 1943 sur Dipetalonema arbuta; Kartman (1956) l'étudie avec précision sur D. immitis, parasitant A. aegypti ; Salt (1963) a montré qu'il s'agissait d'un mécanisme de défense général chez les Arthropodes; la mélanisation est particulièrement fréquente chez les mauvais vecteurs (Highby, 1943).

- Parfois aussi les filaires sont mortes mais ne sont pas recouvertes de granules bruns; leurs extrémités sont floues; de tels parasites, morts d'inanition ou détruits par une substance inconnue, se rencontrent dans les caeca et dans la cavité générale ; ils se reconnaissent à leurs noyaux espacés et faiblement colorables. L'existence de réactions humorales chez les Insectes n'a jamais été prouvée pour les parasites métazoaires ; mais Briggs (1958) et Stephens (1959) semblent avoir démontré son existence vis-à-vis des bactéries. L'observation de destruction de filaires dans l'haemocoele, sans faire intervenir de mécanisme ce.lulaire, ne peut à elle seule prouver la mise en jeu, dans ce cas, de mécanismes humoraux ; on peut penser en effet, comme l'écrit Salt (1963) que la destruction du parasite n'est qu'un effet retardé de substances nocives qui seraient présentes uniquement dans le tube digestif.

- Enfin, il existe un processus de phagocytose, qui semble pius rare : il s'observe non seulement chez les haemocytes, mais aussi chez les cellules digestives; la phagocytose interfère souvent avec la mélanisation; Hughes (1950) et Freer (1953) étudiant les premiers stades du développement de Litomosoüdes carinii chez Ornithonyssus bacoti, ont observé un phénomène semb'able.

Pour Dipetalonema viteae, les destructions sont maximum chez O. erraticus erraticus, la grosse sous-espèce du Maroc, tandis que la peti:e souche originaire de Taghjicht permet le développement d'un certain pourcentage de larves. De telles inégalités de développement entre deux vecteurs de même espèce ont été signalées sur des parasites cosmopolites comme Wuchereria bancrofti (Gaillard, 1932, 1947; Brygoo, 1958; Wharton, 1960 ; Mouchet et coll., 1965), ou Dirofilaria immitis (Noë, 1901 ; Roubaud et coll., 1936; Le Corroler, 1957); mais, dans ces deux cas, le problème est plus complexe: la non réussite du développement du parasite chez. un vecteur donné peut être due à une différenciation géographique soit du parasite, soit de l'hôte.

Comme le matériel sur lequel nous travaillons a une seule source géographique (région de Meched), la variabilité des résultats obtenus ne peut que dépendre du vecteur; nous pensons qu'il doit exister entre les souches d'Ornithodoros erraticus des différences chimiques, assez faibles puisqu'il s'agit d'une même espèce, mais auxquelles Dipetalonema viteae serait très sensible.

Pour tenter de regrouper ces deux phénomènes contradictoires, grande tolérance vis-à-vis des types de cellules parasitées et extrême sensibilité vis-à-vis de certaines différences chimiques existant entre deux hôtes proches, il faut supposer que la filaire a besoin d'un stock de substances de base qui peuvent lui être fournies sous divers aspects chimiques; ainsi les protides myoplasmiques sont facilement remplacés par les 
protides des cellules venimeuses ; mais son développement est aussi conditionné par la présence de facteurs de nature chimique ou physique précis, à répartition très inégale d'une souche à l'autre et même à l'intérieur d'un même hôte; ce pourrait être un facteur inhibiteur chimique ou physique ou, au contraire, un produit indispensable au développement, du type co-enzyme, hormone, etc...

Ainsi, il apparaît bien chez Dipetalonema viteae que la spécificité parasitaire, extrêmement large à certains points de vue, est rendue finalement étroite par des variations aussi précises que minimes des propriétés physico-chimiques du milieu.

C'est là un phénomène qui paraît assez général en parasitologie. Les parasites à l'origine ont une spécificité large, mais la fixité des conditions écologiques auxquelles ils sont soumis, les forçant à reproduire toujours le même cycle, finit par limiter leurs potentialités originelles. L'atrophie morphologique facilement constatable s'accompagne, semble-t-il, d'une atrophie physiologique.

\section{Résumé}

Nous étudions le développement larvaire et le mécanisme d'inoculation de la filaire du Mérion que nous proposons de désigner sous le nom de Dipetalonema viteae (Krepskogorskaya, 1933). L'utilisation des techniques histologiques a permis de mettre en évidence certains éléments qui étaient restés inconnus.

Le développement est d'abord étudié chez le vecteur normal Ornithodoros tartakowskyi: étant donnée la structure uniforme de la paroi des caeca, la sortie des microfilaires se fait en un point quelconque et l'infestation des muscles se fait également au hasard; l'infestation plus forte de la région antérieure de la Tique n'est due qu'à une plus grande richesse en muscles de cette région.

La larve peut détruire totalement les fibres musculaires de petite taille, ne laissant intact que le sarcolemme; dans un muscle suffisamment grand, les destructions sont minimes, très localisées: il y a simplement une petite vacuole de digestion en avant de la région céphalique. Les cellules infestées sont parfaitement réceptives; l'hypertrophie locale de leurs noyaux et de leurs nucléoles suggère l'existence d'une augmentation de leur métabolisme.

Les musc'es, suivant le degré de destruction qu'ils ont atteint, disparaissent totalement et sont nettoyés par les haemocytes, ou persistent à l'état de moignons cicatrisés, ou, étant relativement peu infestés par rapport à leur volume, ne présentent que des lésions difficilement décelables. Constatation très inattendue, des microfilaires ont été trouvées dans les acini venimeux annexés aux glandes salivaires; elles s'y déve. loppent normalement.

Lorsque les larves sont mûres, elles sortent des fibres musculaires et se répartissent au hasard dans la cavité générale sans aucune direction privilégiée; elles sont toutefois plus abondantes là où les organes laissent entre eux des espaces libres, par exemple dans la région du cerveau au-dessus des chélicères.

La piqûre de l'Ornithodore infesté sur un Rongeur provoque une orientation et une migration immédiate des filaires vers la région buccale. Les filaires sortent par 
effraction du salivarium ou de la région antérieure du pharynx. Le passage des filaires n'a été observé que sur des spécimens prélevés au début du repas et ne s'étant pas ou peu gorgés; pour essayer d'expliquer ce phénomène, une étude de l'anatomie du rostre et du mécanisme de l'alimentation a été effectuée; une coaptation entre le labre et la région de l'orifice pharyngien est mise en évidence ; ce système de fermeture du pharynx alternée avec le passage du sang paraît interdire la sortie des filaires pendant la durée de l'alimentation; le courant sanguin pourrait même repousser les filaires, comme semble le montrer la présence de celles-ci dans des caeca ne présentant pas par ailleurs de lésions. Les filaires semblent donc sortir en nombre réduit et sont inoculées dans le derme de l'hôte définitif.

Ornithodoros tartakowskyi se révèle comme un vecteur efficace permettant le développement de presque toutes les filaires qui passent dans la cavité générale; pour mieux apprécier les réactions de défense du vecteur, il a fallu s'adresser à un autre hôte intermédiaire, plus ou moins réfractaire, Ornithodoros erraticus. Les larves sont détruites soit au stade microfilarien, soit après un début de développement; ces larves sont reconnaissables à leur faible colorabilité et à la présence, non constante, de grains de mélanine. La destruction s'observe non seulement dans la lumière des caeca, m̄ais aussi dans certaines cellules digestives, dans la cavité générale, dans les haemocytes et au niveau des muscles eux-mêmes. Le nombre de filaires qui arrivent à maturité varie énormément d'une souche d'O. erraticus à une autre.

L'étroite spécificité du parasite s'oppose à la faculté qu'il a de se développer dans divers organes: les fibres musculaires principalement, mais aussi les tubes de Malpighi, chez $O$. erraticus et, nous l'avons vu plus haut, les acini venimeux chez $O$. tartakowskyi; ces trois sortes d'organes renferment du glycogène. La réussite dans le développement de la filaire ne semble pas tellement dépendre de la forme sous laquelle sont fournis les aliments mais, plus vraisemblablement, de la qualité des unités chimiques qui les constituent: ainsi la myosine peut être remplacée par les protides cytoplasmiques des acini venimeux.

\section{Bibliographie}

ABE (S.), 1937. - Development of Wuchereria bancrofti in the mosquito, Culex quinquefasciatus. J. Med. Ass. Formosa, 36, 482-519. (En japonais, résumé en anglais).

ARTHur (D. R.), 1946. - The feeding mechanism of Ixodes ricinus. Parasit., 37, 154-162.

Arthur (D. R.), 1951. - The capitulum and feeding mechanism of Ixodes hexagonus Leach. Parasit., 41, 66-90.

ARThUR (D. R.), 1957. - The capitulum and feeding mechanism of Dermacentor parumapertus Neumann. Parasit., 47, 169-184.

Baltazard (M.), Chabaud (A.-G.) et Minou (A.), 1952. - Cycle évolutif d'une filaire parasite de Mérion. C.R. Acad. Sc., 234, 2115-2117.

Bernard (P. N.) et Bauche (J.), 1913. - Conditions de propagation de la filariose du Chien ; Stegomya fasciata, hôte intermédiaire de Dirofilaria repens. Bull. Soc. Path. Exot., 6, 89-99. 
Bertram (D. S.), 1939. - The structure of the capitulum in Ornithodoros: a contribution to the study of the feeding mechanism in Ticks. Ann. Trop. Med. Parasit., 33, 229258.

BERTRAM (D. S.), 1947. - The period required by Litomosoides carinii to reach the infective stage in Liponyssus bacoti, and the duration of the mites infectivity. Ann. Trop. Med. Parasit., 41, 253-261.

Bertram (D. S.), Unsworth (K.) et Gordon (R. M.), 1946. - The biology and maintenance of Liponyssus bacoti Hirst 1913 and an investigation into its role as a vector of Litosomoides carinii to cotton rats and white rats, together with some observations on the infection in the white rats. Ann. Trop. Med. Parasit., 40, 228-254.

BLACKLOCK (D. B.), 1926. - The development of Onchocerca volvulus in Simulium damnosum. Ann. Trop. Med. Parasit., 20, 1-49.

BLACKLOCK (D. B.), 1926. - The further development of Onchocerca volvulus Leuckart in Simulium damnosum Theob. Ann. Trop. Med. Parasit., 20, 203-218.

Briggs (J. D.), 1958. - Humoral immunity in lepidopterous larvae. J. Exp. Zool., 138, 155188.

Brug (S. L.), 1932. - Chitinization of parasites in mosquitoes. Bull. Ent. Res., 28, 229-231.

BRYGOO (E.-R.), 1958. — La filariose humaine à Madagascar. Arch. Inst. Pasteur Madagascar, 26, 24-39.

Brygoo (E.-R.), 1960. - Evolution de Foleyella furcata (von Linstow, 1899) chez Culex fatigans Wiedmann, 1828. Arch. Inst. Pasteur Madagascar, 28, 129-138.

BuCKLEY (J. J. C.), 1938. - On Culicoïdes as a vector of Onchocerca gibsoni (Cleland et Johnston, 1910). J. Helm., 16, 121-158.

Buliginskaya (M. A.), Vladimirov (V. L.) et Markov (G. S.), 1959. - Helminthes de l'Ouzbekistan sablonneux avec description d'un nouveau genre de filaire et contribution à l'étude de variations saisonnières de l'Helminthofaune des grandes étendues sablonneuses. Trudi Gelminth. Labor., 9, 55-58 (en russe).

Causey (O. R.), 1939 a. - Aedes and Culex mosquitoes as intermediate hosts of frog filaria, Foleyella sp. Am. J. Hyg., 29, sec. C, 79-81.

Causey (O. R.), 1939 b. - The development of frog filaria larvae, Foleyella ranae in Aedes and Culex mosquitoes. Am. J. Hyg., 29, sec. D, 131-132.

CAUSEY (O. R.), 1939 c. - Development of larval stages of Foleyella brachyoptera in Mosquitoes. Am. J. Hyg., 30, sec. D, 69-71.

Chabaud (A.-G.), 1952. - Le genre Dipetalonema Diesing 1861, essai de classification. Ann. Parasit., 27, 250-285.

Chabaud (A. G.), 1954. - Sur le cycle évolutif des Spirurides et des Nématodes ayant une biologie comparable. Valeur systématique des caractères biologiques. Ann. Parasit., $29,42-88,206-249,358-425$.

Chabaud (A. G.), 1957. - Synonymie de Dipetalonema blanci et de Litosoma vite. Ann. Parasit., 32, 342-343.

Chardome (M.) et Peel (E.), 1951. - Recherches sur la répartition des filaires dans la région de Coquilhatville et la transmission de Dipetalonema streptocerca par Culicoides grahami, Austen. Ann. Soc. Belge Med. Trop., 29, 99-118. 
Connal (A.) et Connal (S. L. M.), 1922. - The development of Loa loa (Guyot) in Chrysops silacea (Austen) and in Chrysops dimidiata (van der Wolp). Trans. Roy. Soc. Trop. Med. Hyg., 16, 64-89.

DESPORTES (C.), 1942. - Forcipomya velox Wim. et Sycorax silacea Curtis, vecteurs d'Icosiella neglecta (Diesing), filaire commune de la grenouille verte. Ann. Parasit., 19, 53-68.

Feng (L. C.), 1936. - The development of Microfilaria malayi in A. hyrcanus var. sinensis Wied. Chinese Med. J., suppl. 1, 345-367.

FRANK (W.), $1964 a$. - Die entwicklung von Macdonaldius oschei Chabaud et Frank 1961 (Filarioidea, Onchocercidae) in der Lederzecke Ornithodorus talaje Guérin Meneville (Ixodoidea, Argasidae), Z. f. Parasit., 24, 319-350.

FraNK (W.), $1964 b$. - Die Uebertragung der Filarien-infektionstadien von Macdonaldius oschei ein Beitrag zur Biologie des Ueberträgers. Z. f. Parasit., 24, 415-441.

Freer (P. M.), 1953. - Observations on the early fate of the microfilariae of Litomosoides carinii (Travassos, 1919), filarial parasite of the cotton rat, after their ingestion by the vector, Bdellonyssus bacoti (Hirst, 1913). Ann. Trop. Med. Parasit., 47, 13-25.

Galliard (H.), 1932. - Recherches sur les filarioses au Gabon Occidental. Bull. Soc. Path. exot., $25,167-174$.

Galliard (H.), 1941. - Recherches sur le mécanisme de la transmission des filaires par les Culicidés. Ann. Parasit., 18, 209-214.

Galliard (H.), 1947. - Evolution de Wuchereria bancrofti et W. malayi chez Aedes aegypti et A. albopictus. Ann. Parasit., 22, 30-35.

Gibirns (E. G.), 1938. - The mouth part of the female in Simulium damnosum Theobald with special reference to the transmission of Onchocerca volvulus Leuckart. Ann. Trop. Med. Parasit., 32, 9-20.

Gordon (R. M.) et Crewe (W.), 1953. - The deposition of the infective stage of Loa loa by Chrysops silacea, and the early stages of its migration to the deeper tissues of the mammalian host. Ann. Trop. Med. Parasit., 47, 74-85.

Gregson (J. D.), 1960. - Morphology and functionning of the mouth parts of Dermacentor andersoni. Acta trop. (Bâle), 17, 48-79.

Highby (P. R.), 1943. - Dipetalonema arbuta n. sp. (Nematoda) from the porcupine, Erethizon dorsatum (L.). J. Parasit., 29, 239-242.

Hopkins (C. A.) et Nicholas (W. L.), 1952. - Culicoides austeni, the vector of Acanthocheilonema perstans. Ann. Trop. Med. Parasit., 46, 276-283.

Hughes (T. E.), 1950. - Some stages of Litomosoides carinii, in Lyponyssus bacoti. Ann. Trop. Med. Parasit., 44, 285-290.

Kartman (L.), 1956. - Notes on the encapsulation of Dirofilaria immitis in the mosquito Aedes aegypti. Ann. Vet. Res., 17, 810-812.

KeRShAw (W. E.), 1948. - Observations on Litomosoides carinii (Travassos, 1919) Chandler 1931. I: the development of the first stage larva. Ann. Trop. Med. Parasit., 42, $377-$ 399.

KLeINE (F. K.), 1915. - Die Uebertragung von Filarien durch Chrysops. Z. f. Hyg. u. Infektionskr., 80, 345-349.

Annales de Parasitologie humaine et comparée (Paris), t. 42, 1967, $\mathrm{n}^{\circ} 2$ 
Landau (I.) et Chabaud (A. G.), 1965. - Infection naturelle par deux Plasmodium du Rongeur Thamnomys rutilans en République Centrafricaine. C.R. Acad. Sc., 260, 230-232.

LAVOIPIERRE (M. M. J.), 1958. - Studies on the host-parasite relationships of filarial Nematodes and their arthropod hosts. I. - Sites of development and the migration of Loa loa in Chrysops silacea, the escape of the infective forms from the head of the fly, and the effect of the worm on its insect host. Ann. Trop. Med. Parasit., 52, 103121. II. - The Arthropod as a host to the Nematode : a brief appraisal of our present knowledge based on a study of the more important literature from 1878 to 1957. Ann. Trop. Med. Parasit., 52, 326-345.

LEBIED (B.), 1950. — Une nouvelle théorie endémiologique : sur le rôle de la fonction du parasitisme $\times$ mécanisme du vol du vecteur comme facteur décisif de l'établissement du foyer de l'endémicité de l'onchocercose et de filarioses en général. Dijon. Imprimerie Darantière. 54 pp.

-, 1961. - Introduction à la théorie de l'évolution inirasyncytiale des Filariata. I. Sur la phagocytose des microfilaires Onchocerca volvulus par les fibres musculaires thoraciques chez Simulium. Rev. di. Parasit., 22, 107-136.

Le Corroler (Y.), 1957. - Evolution de Dirofilaria immitis Leidy 1856, chez Aedes (Stegomyia) aegypti, Lin., souche «Orlando» (Floride). Bull. Soc. Path. Exot., 50, 542555 .

Mc Intosh (A.) et Mc Intosh (G. E.), 1935. - Additional note on two bat parasites Dicrocoelium lasium Mc Intosh, 1933 and Litomosa americana. Proc. Helm. Soc. Wash., 2, 60-62.

Mackerras (M. I.), 1953. - Lizard Filaria : transmission by mosquitoes of Oswaldofilaria chlamydosauri (Breinl) - (Nematoda : Filarioidea). Parasit., 43, 1-3.

Mouchet (J.), Grjebine (A.) et Grenier (P.), 1965. - Transmission de la filariose de Bancroft dans la région éthiopienne. Cahiers de l'O.R.S.T.O.M., Entomologie médicale, $\mathrm{n}^{\circ} 3-4,67-90$.

Nelson (G. S.), 1961. - On Dipetalonema manson-bahri n. sp., from the Spring-hare Pedetes surdaster larvalis, with a note on its development in fleas. J. Helm., 35, 143-160.

-, 1962. - Dipetalonema reconditum (Grassi, 1889) from the Dog, with a note on its development in the flea Ctenocephalides felis and the louse, Heterodoxus spiniger. J. Helm., 36, 297-308.

—, 1963. - Dipetalonema dracunculoïdes (Cobbold, 1870) from the dog in Kenya with a note on its development in the louse-fly, Hippobosca longipennis. J. Helm., 37, 235-240.

Newton (W. L.) et Pratt (I.), 1945. - Experiments to determine whether infective larvae of Wucheria bancrofti can migrate from the abdomen of the mosquitoe intermediate host. J. Parasit., 31, 266-268.

NoÉ (G.), 1901. - Sul ciclo evolutivo della Filaria bancrofti (Cobbold) et della Filaria immitis - (Leidy). Ric. Lab. Anat. norm. Univ. Roma, 8, 277-353.

-, 1908. - Il ciclo evolutivo della Filaria grassii mihi 1907. Rend della R. Acc. dei Lincel., $17,282-291$.

Petithory (J.), 1965. - Les phosphomonoestérases des microfilaires de Loa loa (Guyot 1778). C.R. Séances Soc. Biol., 159, 569-571.

Pistey (W. R.), 1956. - Studies on the mosquito transmission of Dirofilaria tenuis Chandler, 1942. J. Parasit., 42, Suppl. p. 16. 
Roubaud (D.) et Decazeaux (J.), 1921. - Contribution à l'histoire de la mouche domestique comme agent vecteur des Habronémoses d'Equidés. Cycle évolutif et parasitisme de l'Habronema megastoma (Rudolphi, 1819) chez la mouche. Bull. Soc. Path. Exot., 14, 471-506.

—, 1922. - Deuxième contribution à l'étude des mouches dans leurs rapports avec l'évolution des Habronèmes d'Equidés. Bull. Soc. Path. exot., 15, 978-1001.

Roubaud (E.), Colas-Belcour (J.), Toumanoff (C.) et Treillard (M.), 1936. - Recherches sur la transmission de D. immitis Leidy. Bull. Soc. Path. Exot., 29, 1111-1180.

SCHACHER (J.F.), 1962. - Morphology of the microfilaria of Brugia pahangi and of the larval stages in the mosquito. J. Parasit., 48, 679-692.

Sноно (C.) et NaIR (V. K.), 1960. - Studies of cerebrospinal Nematodiasis in Ceylon. (VII). Experimental production of cerebrospinal Nematodiasis by the inoculation of infective larvae of Setaria digitata into susceptible goasts. Ceylon Veterinary J., 8, 2-12.

STEPHENS (J. M.), 1959. - Immune responses of some Insects to some bacterial antigens. Canad. J. Microbiol., 5, 203-228.

Steward (J. S.), 1932. - Onchocerca cervicalis (Railliet et Henry, 1910) and its development in Culicoïdes nubeculosus Mg. Univ. Cambridge Inst. Anim. Path. Rep. of Direct, 3th Rep., 272-284.

-, 1937. - The occurence of Onchocerca gutturosa in cattle in England with an account of its life history and development in Simulium ornatum Mg. Parasit., 29, 212-219.

TERry (A.), Terry (R. J.) et Worms (M. J.), 1961. - Dipetalonema witei, filarial parasite of the jird Meriones libycus. II. The reproductive system, gametogenesis and development of the microfilariae. J. Parasit., 47, 703-711.

Wattiaux (M.), 1964. - Contribution à l'étude de la filariose expérimentale du mérion et du hamster par Dipetalonema witei. Thèse pour le Diplôme de Doctorat d'Université en pharmacie. Faculté mixte de Médecine et Pharmacie de Lille, 83 pp. polycopiées.

Weber (W. A. F.), 1955. - Dirofilaria aethiops Weber 1955, a filarial parasite of Monkeys. III. The larval development in mosquitoes. Parasit., 45, 388-400.

Weber (W. A. F.) et Hawking (F.), 1955. - Experimental maintenance of Dirofilaria repens and Dirofilaria immitis in Dogs. Exp. Parasit., 4, 143-164.

Wharton (R. H.), 1957. - Studies on filariasis in Malaya : observations on the development of Wuchereria malayi in Mansonia (Mansionoïdes) longipalpis. Ann. Trop. Med. Parasit., 51, 278-296.

—, 1960. - Studies on filariasis in Malaya : field and laboratory investigations of the vectors of a rural strain of Wuchereria bancrofti. Ann. Trop. Med. Parasit., 54, 78-99.

Williams (R. W.), 1948. - Studies on the life cycle of Litomosoides carinii, filariid parasite of the cotton rat, Sigmodon hispidus litoralis. J. Parasit., 34, 24-43.

Worms (M. J.), Terry (R. J.), Terry (A.), 1961. - Dipetalonema witei, filarial parasite of the jird Meriones libycus. I. Maintenance in laboratory. J. Parasit., 47, 963-970.

YEN (C. H.), 1938. - Studies on Dirofilaria immitis Leidy, with special reference to the susceptibility of some Minnesota species of mosquitoes to the infection. J. Parasit., 24, 189-205.

[Laboratoire de Zoologie (Vers), Muséum National d'Histoire Naturelle 57, rue Cuvier, Paris-5 $\left.{ }^{\circ}\right]$ 